\title{
Linguistic categories and their utilities: The case of Lao landscape terms
}

\author{
N.J. Enfield \\ Language and Cognition Group, Max Planck Institute for Psycholinguistics, PB 310, \\ 6500 AH Nijmegen, Netherlands
}

\begin{abstract}
Different domains of concrete referential semantics have provided testing grounds for investigation of the differential roles of perception, cognition, language, and culture in human categorization. A vast literature on semantics of biological classification, color, shape and topological relations, artifacts, and more, raises a range of theoretical and analytical debates. This article uses landscape terms to address a key debate from within research on ethnobiological classification: the opposition between so-called utilitarian and intellectualist accounts for patterns of lexicalization of the natural world [Berlin, B., 1992. Ethnobiological Classification: Principles of Categorization of Plants and Animals in Traditional Societies. Princeton University Press, Princeton, NJ]. 'Utilitarianists' argue that lexical categories reflect practical consequences of knowing certain category distinctions, related to cultural practice and functional affordances of referents. 'Intellectualists' argue that lexical categories reflect people's innate interest in the natural world, combined with the perceptual discontinuities supplied by 'Nature's Plan'. The debate is generalizable to other domains, including landscape terminology, the topic of this special issue. This article brings landscape terminology into this larger debate, arguing in favor of a utilitarian account of linguistic categories in the domain of landscape, but proposing a significant revision to the concept of utility in linguistic categorization. The proposal is that for LINGUISTIC categorization, what is at issue is not (primarily) the utility of the REFERENT (e.g. a river), but the utility of THE WORD (e.g. the English word river). By considering how landscape terms are actually used in conversation, we see that they are deployed in communicative contexts which fit a rich, 'functionalist' semantics. A landscape term is not employed for mere referring, but functions to bring particular associated ideas into social discourse. In turn, language use reveals a range of evidence for the semantic content of any such term, of utility both to the language learner and to the semanticist. This kind of evidence can be argued to underlie the acquisition of semantic categories in
\end{abstract}

E-mail address: nick.enfield@mpi.nl 
language learning. The arguments are illustrated with examples from Lao, a Tai language of mainland Southeast Asia.

(C) 2007 Elsevier Ltd. All rights reserved.

Keywords: Landscape terminology; Laos; Categorization; Semantics; Culture; Cognition

\section{Introduction}

'Most of our categorical furniture is cultural and ... its presence in our minds is not guaranteed by the sensible attributes of the categories themselves. We need some sort of indication from those who participate in the culture of the things they treat as equivalents and those that are distinguished'. (Roger Brown, 1958, Words and Things, p. 208)

The analysis of referentially concrete semantics has long been considered a lens for examining the relation between language, perception, and mind. Among the fundamental controversies is the question of semantic content. Are the meanings of words derived from our perceptual experience of their referents, or are they conceptually constructed by rational means? Or is it a combination? The issue is far from resolved. This article brings new data to bear on the problem, exploring the notion of utility in the semantics of terms for features of the natural landscape. Landscape is a good domain for further exploration of the question of folk classification of the world, but it is so far yet to be included in the discussion. The data to be discussed here are words for geographical features in Lao, a Southwestern Tai language of Laos, Thailand, and Cambodia. I argue that a proper understanding of the meanings of landscape terms (as for any other semantic domain) demands a sound conceptual analysis of just what sort of a thing linguistic meaning is. I explore a conceptual basis for understanding the problem of linguistic meaning, from which it emerges that debates of whether word meaning is based on 'utility' or 'perceptual discontinuity' of word referents miss the mark, since they are of direct relevance to categorization in general but only of indirect relevance to LINGUISTIC categorization. I argue for a utilitarian position, but one which differs significantly to that of Hunn $(1982,1985)$ and like-minded researchers. I propose that word meanings are guided primarily by the utility OF THE WORD, not of the word's referent. Data from conversation show how people use words to strategically bring certain kinds of ideas into discourse, not (primarily) to 'map words onto the world'. If we establish that the word's function is to achieve social and conceptual coordination, we see the linguistic and social context as being the word learner's key source of information enabling them to construct semantic categories in language acquisition, and to maintain semantic categories in language competence.

\section{Meanings of Lao landscape terms: a sketch of the domain}

We begin with a sketch of the set of terms in Lao which any Lao-speaking child must acquire in order to appropriately refer to features of the natural domain of landscape. In the context of this comparative special issue, this section serves first as a descriptive contribution, and second as a prerequisite to the theoretical point of the article, which bears 
directly upon the semantics of landscape terminology, and more generally upon the semantics of referential terminology in any semantic domain, extensional or otherwise (cf. Wierzbicka, 1989). This sketch of Lao landscape terms is not exhaustive, but is intended to give an overview of the main distinctions. The data are from interviews with Lao speakers during field trips in the Vientiane area and in Nakai district of Khammouane Province in 2004 and 2005. This is complemented with reference to recordings of language in use, and other experience with the language in field trips to Lao-speaking areas since 1990.

\subsection{The environment of Lao speakers}

Laos is a tropical country wedged between Cambodia, Vietnam, China, Myanmar, and Thailand (see Fig. 1).

Lao speakers are the dominant ethnic group in Laos, making up about half of the country's total population of some five million. There are between 60 and 100 distinct ethnolinguistic groups distributed across the country (see Enfield, 2006a). A large proportion of the area is mountainous, the highest peak reaching almost $3000 \mathrm{~m}$. However, Lao speakers stick to the lowlands. They refer to their own ethnic group as laaw2 lum1 'Low Lao'

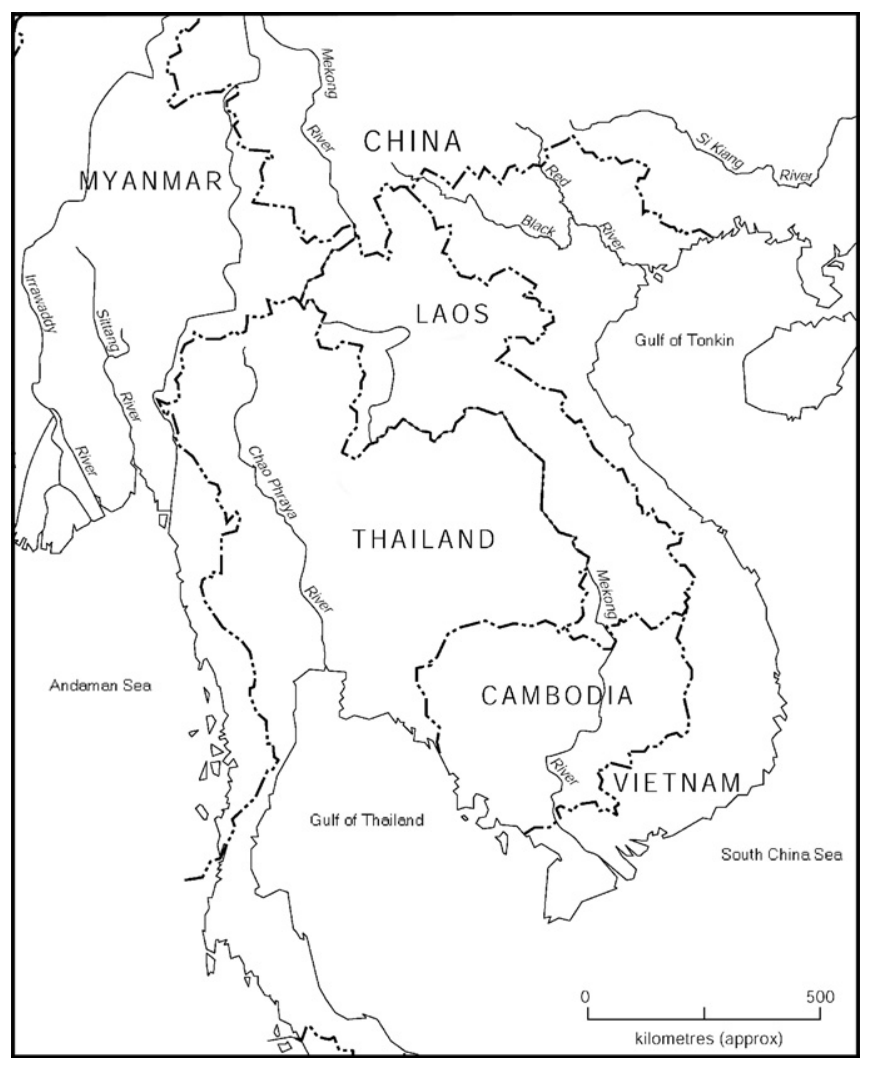

Fig. 1. Map of Laos and surrounding countries, political, with rivers. 
because they inhabit the country's plains and lower lands (mostly concentrated along the banks of the Mekong river and associated lowland areas). Their two other macro-ethnic categories are laaw2 theng2 'Upper Lao', referring to speakers of Austroasiatic languages, and laaw2 suung3 'High Lao', referring to speakers of Hmong-Mien and Tibeto-Burman languages. Lao speakers' preference for flatter land near major rivers is tied to their livelihood focus on the control of large quantities of water for irrigation of paddy rice. They practice supplementary hunting and gathering in neighboring forest and upland areas.

The lowland areas preferred by Lao speakers will, in their natural state (i.e. not yet transformed into paddy fields or gardens) typically be relatively dry, spacious, forest environments (known in Lao as khook4; see Fig. 12). This kind of land will often adjoin denser evergreen forest in elevated areas. The denser, elevated forest is normally used by Lao speakers for hunting and gathering, and may also be used for supplementary swidden (i.e. slash-and-burn) agriculture. (For many people of Laos who speak languages other than Lao - the so-called Upper Lao and High Lao - swidden agriculture in upland areas is the norm.) (see Fig. 2)

Lao speakers' lowland habits are seated in a deep heritage as members of a Tai ethnicity. Large-scale Tai spreads from modern-day southwestern and southern China over the last two millennia were driven in a southwesterly direction by the search for flat lands which provide for irrigated paddy agriculture (Wyatt, 1984; Enfield, 2003, pp. 47-50). The typical Tai settlement features the village surrounded by paddies on the flat lands, with any mountainous terrain in the vicinity rising above the village, away from where most of daily life is conducted (Condominas, 1990; Leach, 1964/1954; Wyatt, 1984). Mountainous terrain in Lao-speaking areas is often inhabited by people of other ethnicities such as speakers of Mon-Khmer, Hmong-Mien, or Tibeto-Burman languages.

We now sketch the meanings of Lao terms for features of the landscape in three categories: water features, convex/gradient features, and forest types.

\subsection{Water features}

The Lao word nam4 refers to water as well as liquid in general. ${ }^{1}$ It is widely used in the Lao lexicon as a class term in words for different kinds of liquid (e.g. nam4-man2 'oil' (literally 'oily water'), nam4-taa3 'tears' (literally 'eye water'), nam4-nom2 'milk' (literally, 'breast water'); Enfield, 2004a, p. 134). The word nam4 alone is often sufficient for referring to rivers and other larger watercourses. There are, however, ways to be more specific in referring to water features in the landscape.

There are three main terms for sizable, flowing watercourses of different types: mèe 1nam4, huaj5, and hò̀ng1. The term mè̀l-nam4, literally 'water mother', is close to the meaning of English river. A referent of this term will be a large watercourse, with significant flow, never running dry, very long, a considerable obstacle to land travel (across), probably a considerable affordance to water travel (along), and a place to find large fish. The significance of the specification 'never running dry' is the monsoonal climate in Laos. There is little rain fall between about November and April, which means that many smal-

\footnotetext{
${ }^{1}$ Numerals at the end of Lao words signify lexical tone: 1 (mid level), 2 (high rising), 3 (low rising), 4 (high falling), 5 (low falling).
} 
a

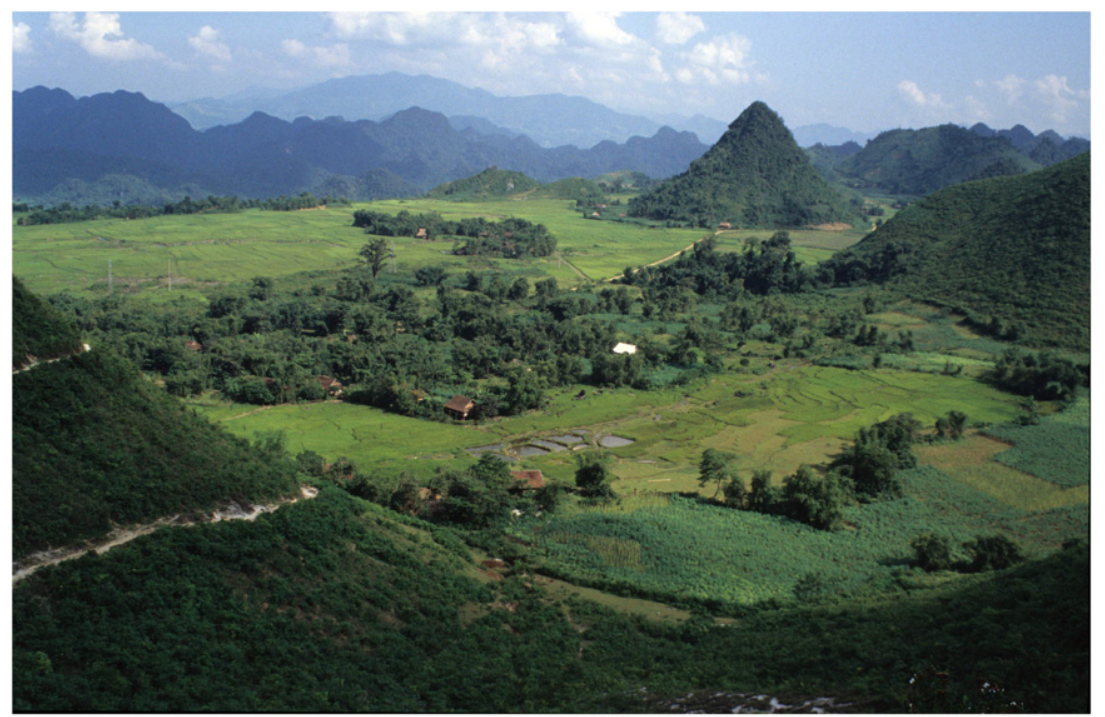

b

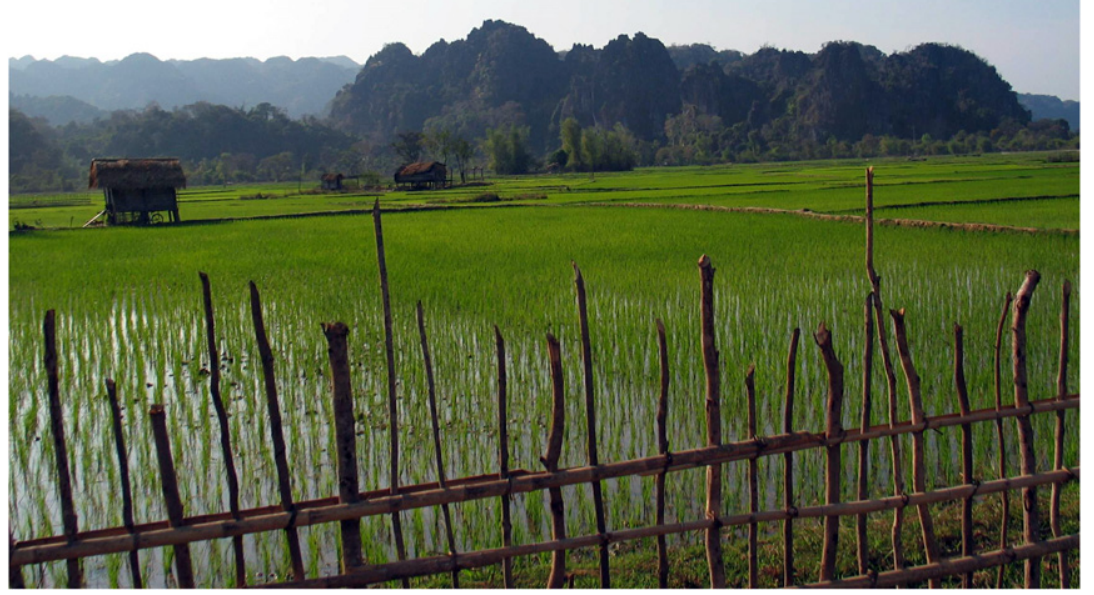

Fig. 2. Typical Tai settlements: paddy and village on flat land, with mountainous terrain apart.

ler watercourses can run dry. The notion of 'mother' incorporated in the term mèel-nam4 relates to the status of a larger river as single, larger unit, with multiple smaller, subsidiary units (tributaries). (Cf. mè̀l mùù2 'thumb', literally 'mother of the hand'.) Note, however, that this is as far as the metaphor goes: tributaries are not referred to as 'children'. In terms of size, a mè l-nam4 may be anything from $50 \mathrm{ft}$ to a mile or more across (e.g. the Mekong) (see Fig. 3). 


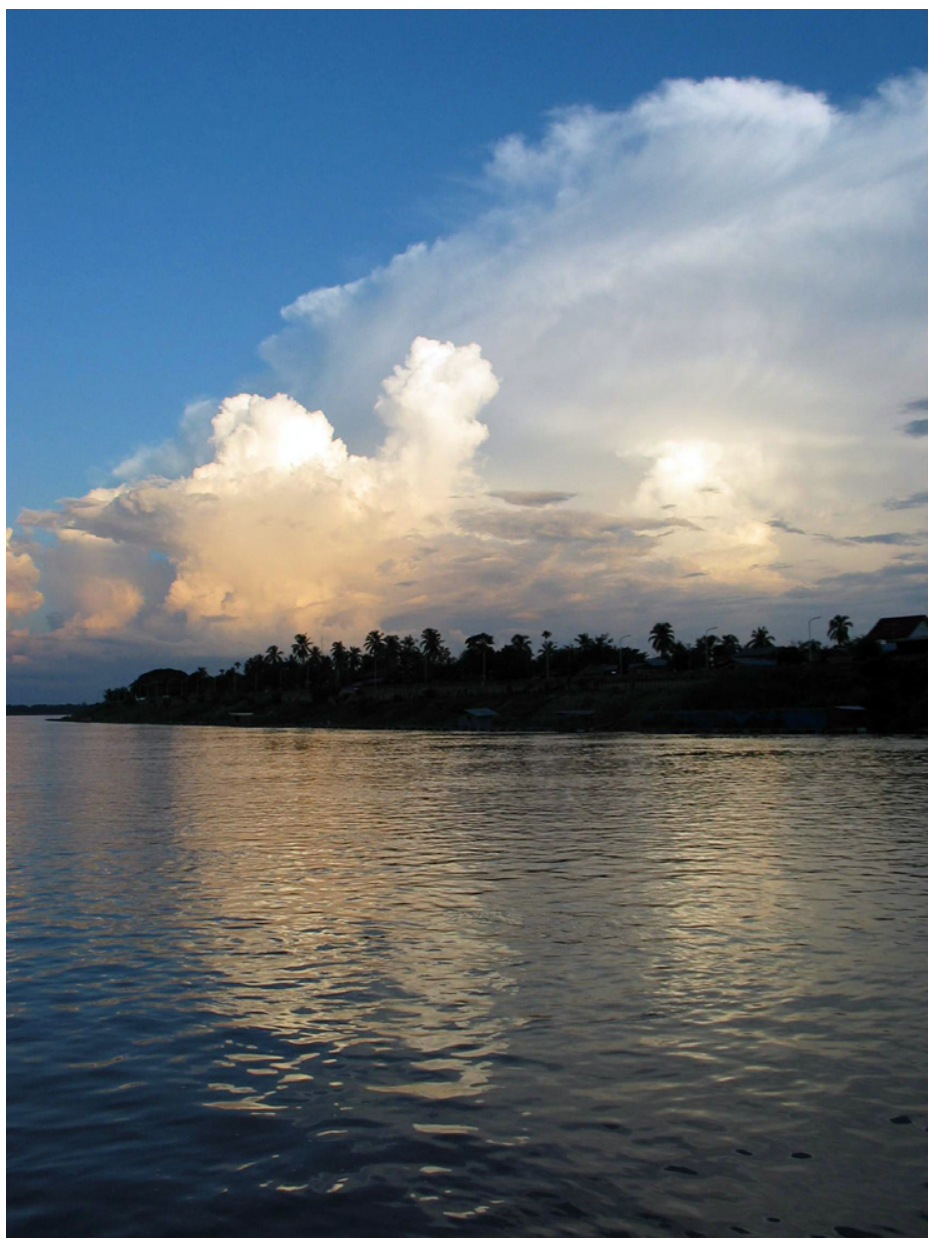

Fig. 3. A large mè̀l-nam4 'river' - the Mekong at Vientiane, Laos.

Small tributaries are called huaj5 'creek, stream' if they are small enough to be normally crossable without a boat (i.e. by walking or wading across), if they may become dry or a trickle in the dry season, if they do not afford travel along. While a mèel-nam4 undergoes noticeable change from season to season (differences from dry to wet season in color, level of water, flow, accessibility), these differences do not transform it in terms of human interaction. No matter what time of year, it is never easy to cross a mèè-nam4. By contrast, a huaj5 'creek, stream' presents a significantly different set of constraints and affordances from season to season. At the height of the rainy season, a huaj5 'creek, stream' may become deep and possibly treacherous to cross, while on the other hand may temporarily afford boat travel along (see Fig. 4).

The term hò̀ngl 'brook' refers to another type of smaller tributary, a shallower, faster flowing, less narrow channel than a huaj5 (see Fig. 5).

Watercourses of all sizes have distinguishable parts in Lao, including khèèn2 'bank', fangl 'side', haat5 'beach, sand bank', dò̀n3 'island', nò̀t4 'source' (literally 'peak'), 


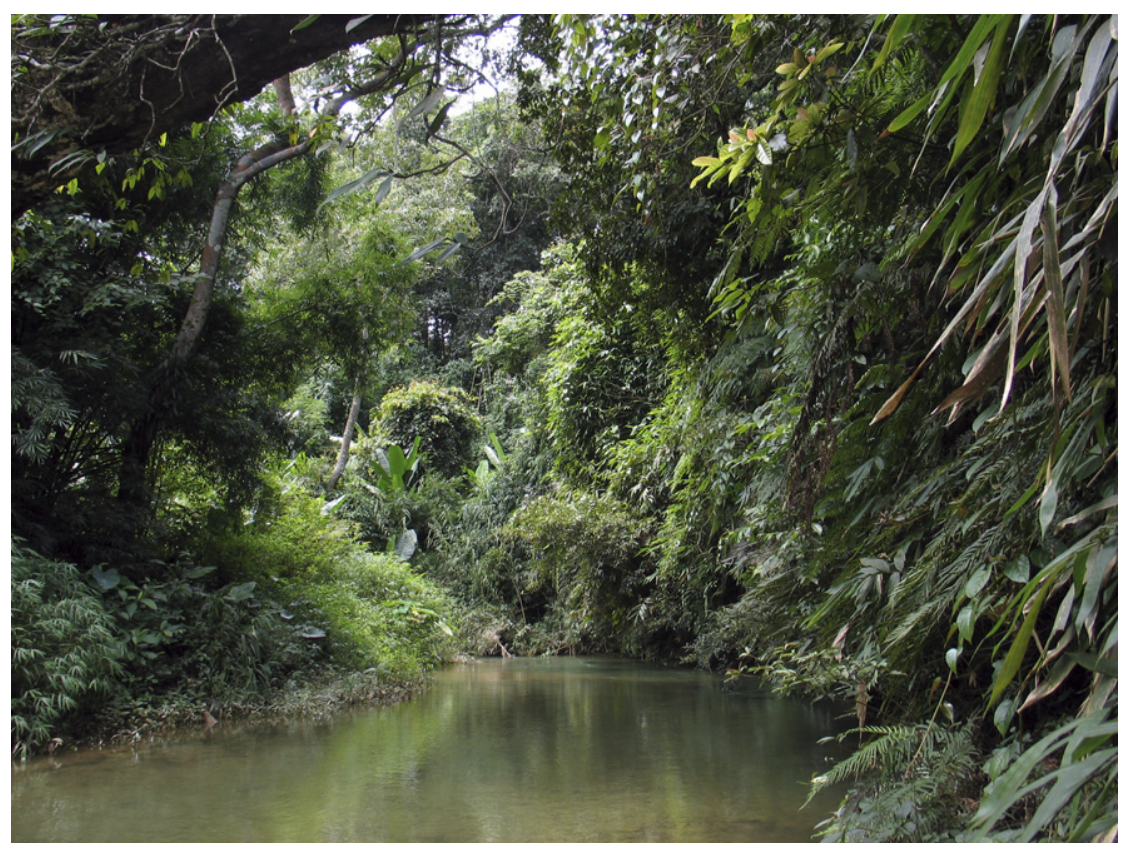

Fig. 4. Typical referent of the Lao word huaj5 'creek, stream'.

paak5 'mouth', and naa5 '(water) surface' (literally 'face of the water'; cf. 'back of the water' for the same feature in Jahai; Burenhult, this issue).

There are two main terms for falling water features in Lao: taat5 'low flowing falls with flat, shallow base', and nam4 tok2 (literally 'falling water') 'high water fall'. The terms taat5 and nam-tok2 have some referential overlap: that is, certain types of landscape feature can be labeled using either word. It is sometimes applicable to combine the two terms, as nam4 tok2 taat5, to refer to feature where a relatively high fall of water drops onto a flat, shallow, accessible base. Typically, a taat5 is a place where one can go and 'play', swimming in and around the base of the falling water feature (see Fig. 6).

Critically, a taat 5 does not empty into a deep pool, but onto rocks. The term taat5 refers as much to this flat area on which the water lands as it does to the falling water. A nam4-tok2, by contrast, is often much taller, and relatively inaccessible (see Fig. 7).

The term kèèngl refers to an 'area of swollen waters'. This term may also be used as a verb to denote a temporary state of 'having swollen waters'. When water is said to be in a state of kèengl, this normally implies that it is difficult to cross - e.g., where normal travel routes such as roads, paths, or crossings are flooded. Terms more specifically referring to flooding (rather than flooded places) are nam4 maak4 literally 'water a lot', describing temporary high levels of flowing water in a water course (e.g. due to recent heavy rain), and nam4 thuaml 'water flooding', where water breaks the banks and covers normally dry land.

There are three common terms for water features with no visible flow: vang2 'river pool', bùng3 'swamp', and nò̀ng3 'lake'. A referent of the term vang2 will be a large pool in a river or stream, where the water is relatively deep and not perceptibly flowing. 


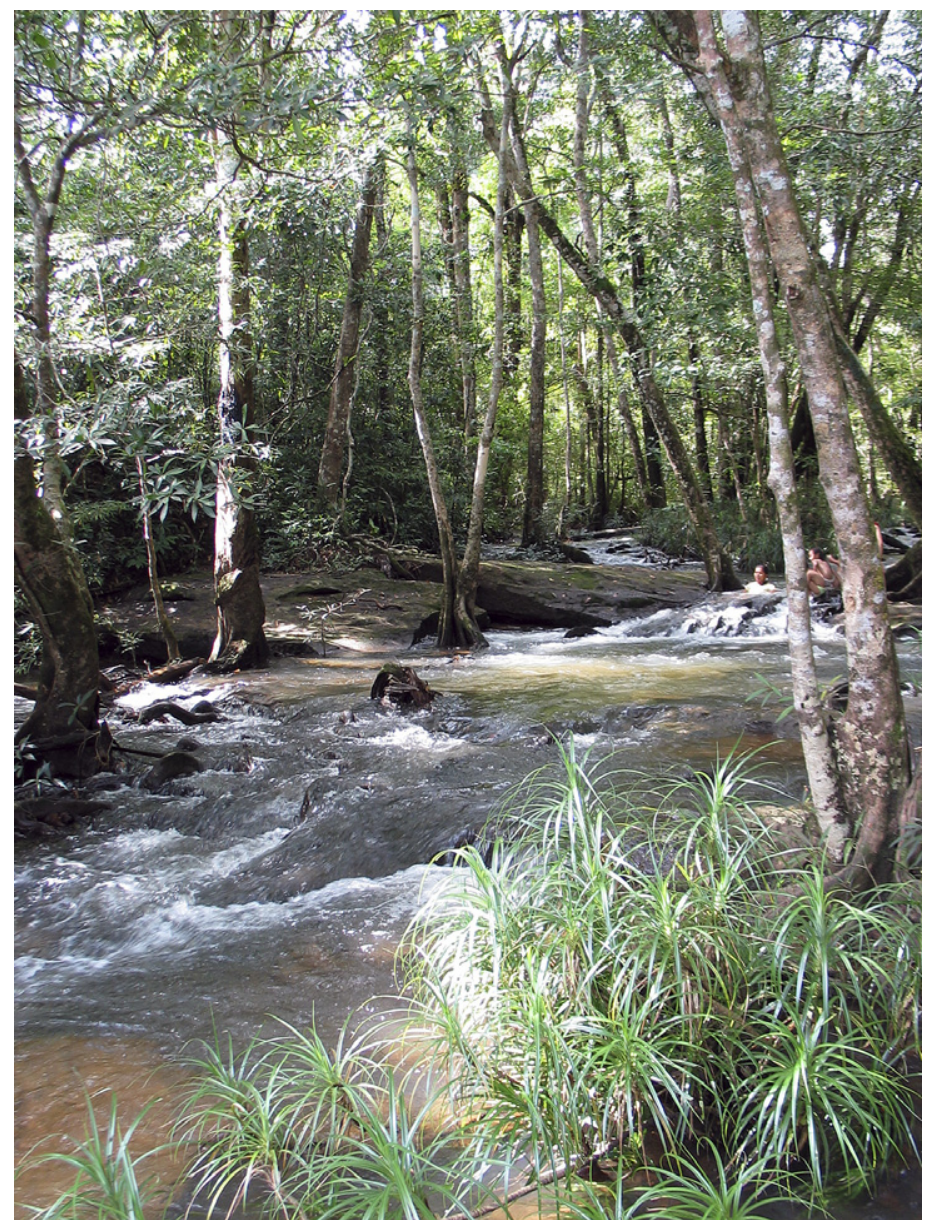

Fig. 5. Typical referent of the Lao word hò̀ngl 'brook'.

Prototypically, a vang2 has towering forest along its banks, and the area is considered spooky, and inhabited by spirits (Fig. 8).

The terms bùng3 and nò̀ng3 also refer to expanses of water with no visible flow, but these are found in more open environments. These two words both refer to naturally occurring water features which are not perceptibly flowing, which are difficult to get close to (without getting your feet wet), and which harbor thick vegetation and wildlife of particular kinds. Comparable words in English are swamp and marsh, extending also into lake and pond (see Fig. 9).

When asked how the feature pictured in Fig. 9 should be referred to, Lao speakers say bùng3, nò̀ng3, or both. Key differences between the terms bùng3 and nò̀ng3 are not visibly represented in Fig. 9, but they emerge in interviews. A bùng3 is said to be shallow in comparison to a nò̀ng3. It is said to have thicker vegetation. A nò̀ng3 is said to be more variable in size and appearance - it can range from a swamp-like stream overflow to an open lake. A bùng3 is a large place which may have sections of open water, swampy 


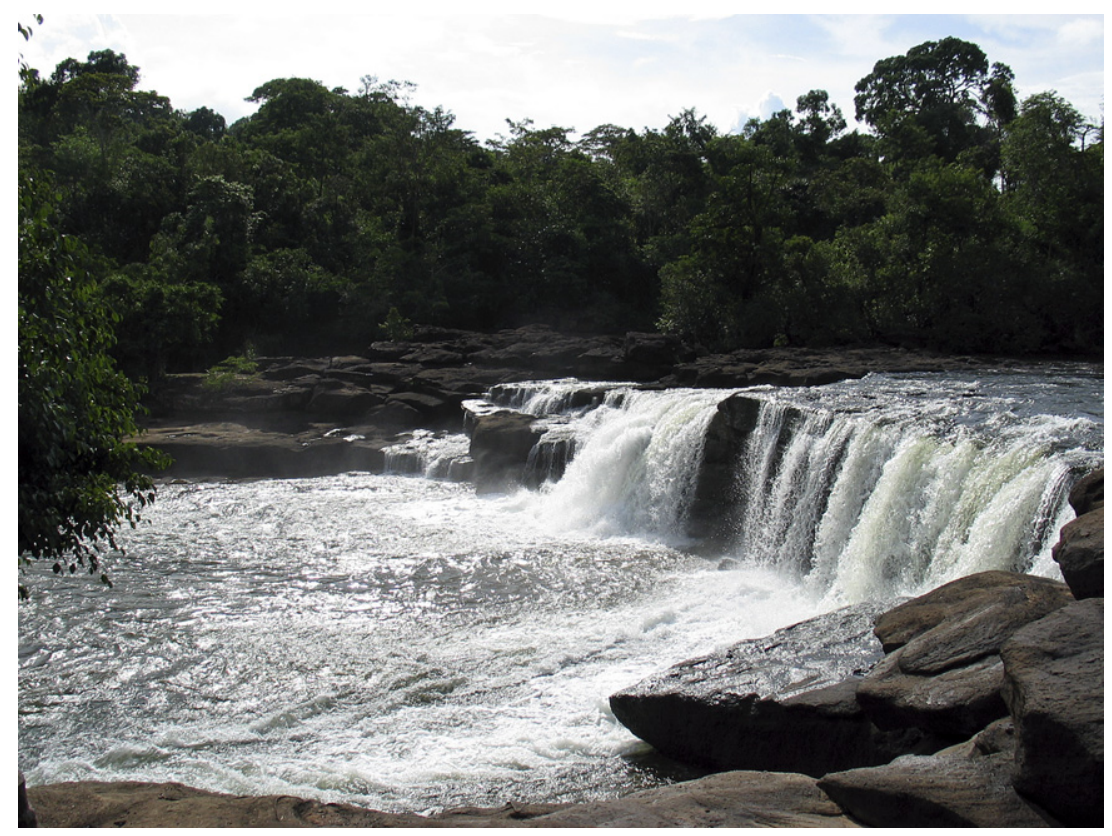

Fig. 6. Typical referent of the Lao word taat5: low, flowing falls on onto shallow, flat rock area.

sections filled with reeds and other growth, and sections of grassy ground. It is not thought of as part of some other landscape feature. A nòng3, on the other hand, may be a small feature alongside a watercourse (river, stream, etc.). While both types of feature are sites for similar kinds of foraging and hunting activity (collecting edible vegetation, fishing with certain types of gear), a nòng3 is considered to be less inviting for such activity, since it is normally thought of as having deeper water.

There are several terms for water features made by people. These include saq2 'pond, pool (for raising fish, or swimming)', khòòng2 'canal, channel', mùang3 'canal for irrigation', khuu2 'dam', faaj3 'weir', qaangl 'reservoir'.

Finally, while there are no saltwater bodies in Lao-speaking areas, the language does have terms for sea features: thalêê2 'sea', samut1 'ocean', qaaw1 'bay', kòq2 'sea island'. These words appear to have the same meanings as their counterparts in Thai.

\subsection{Convex/gradient features (mountains, hills, slopes, etc.)}

Lao does not have a term equal in meaning to English mountain. The term phuu2 may be more accurately glossed as 'mountainous terrain', as depicted in Fig. 10.

A land form which in English may be called an individual mountain (e.g. the coneshaped elevation in Fig. 2a) can be referred to in Lao by using a complex numeral classifier phrase (Enfield, 2004a, pp. 118-128). Thus, phuu2 nuaj1 nii4 [mountainous_terrain clf_unit this] means 'this mountain' (literally 'this unit of mountainous terrain'). This suggests that in the Lao imagination, there is no 'thing' corresponding to English mountain. That idea is only secondarily derived from a more basic notion of mountainous terrain as "mass". A term which does refer to a single 'unit' of raised ground is phoon2 'mound, hillock', 


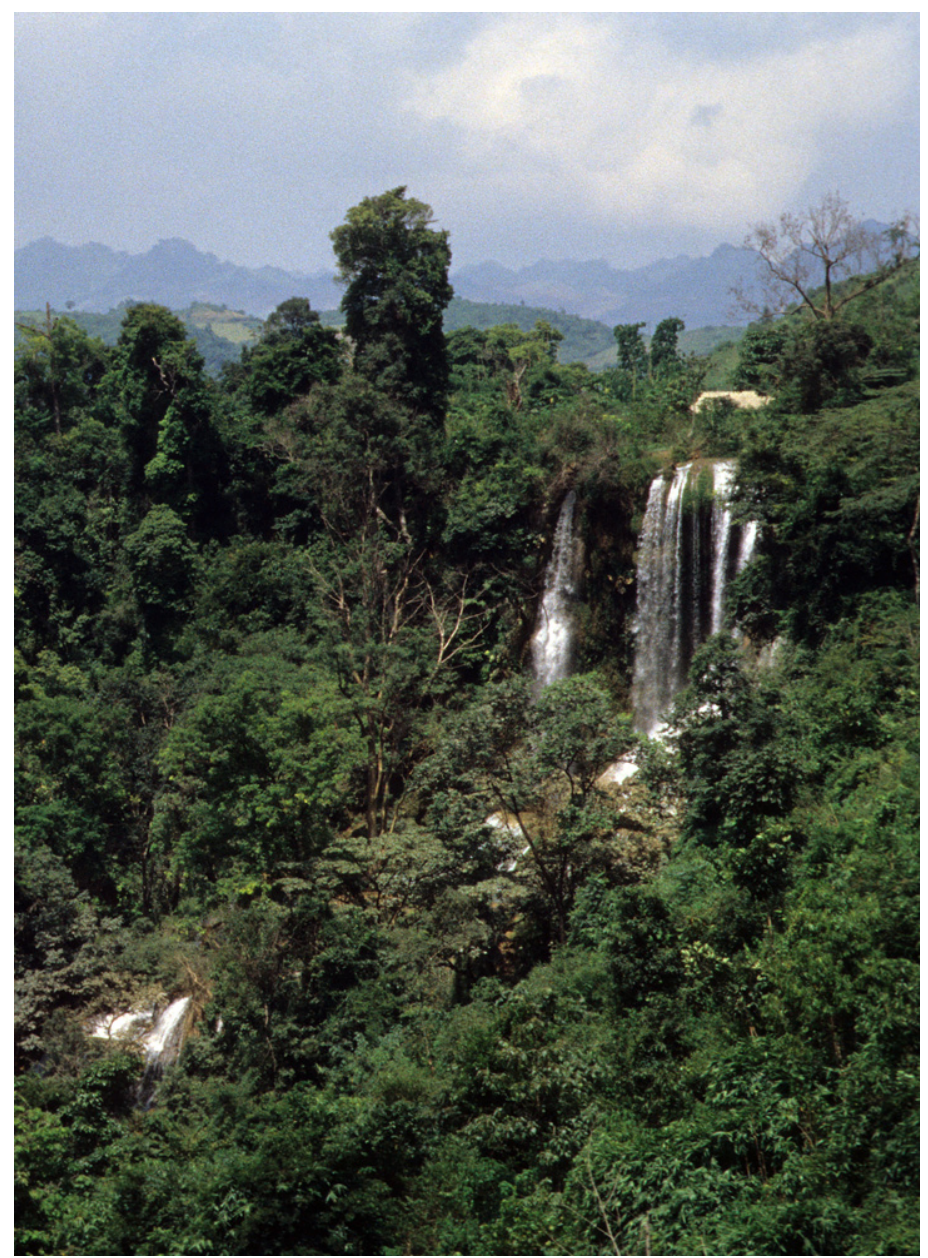

Fig. 7. Typical referent of the Lao word nam4 tok2 'waterfall'.

generally somewhat small. The term phoon 2 may be used to refer to something as small as a termite mound, and probably not much bigger than a house.

In accordance with the lowland lifestyle of Lao speakers, there is an idea that phuu 2 'mountainous terrain' is far away from where people live, typically thought of as difficult to travel in/on, due to being steep and forested with jungle (dong3; see Section 2.4). If such terrain is not forested, it may have been transformed by agricultural activity in the form of hajl 'swidden fields' (i.e., slash-and-burn fields; see Fig. 15). There are several terms referring to parts or features of phuu2 'mountainous terrain', including cò̀m3 'acme', ñòt4 'peak', neen2 'foot hill', tiin3 'foot of hill', san3 'ridge', and saaj3 'range, chain'. A plateau is referred to as phuu2 phiang2 'flat (topped) mountainous terrain'. There is no word in Lao corresponding to the complex notion of English valley. Instead there are simpler notions for various types of sloping land, including noon2 'rise', khòoj4 'locally sloping area of land' (usually, as a path up or down), and hêew3 'cliff, ravine'. The term phaa3 


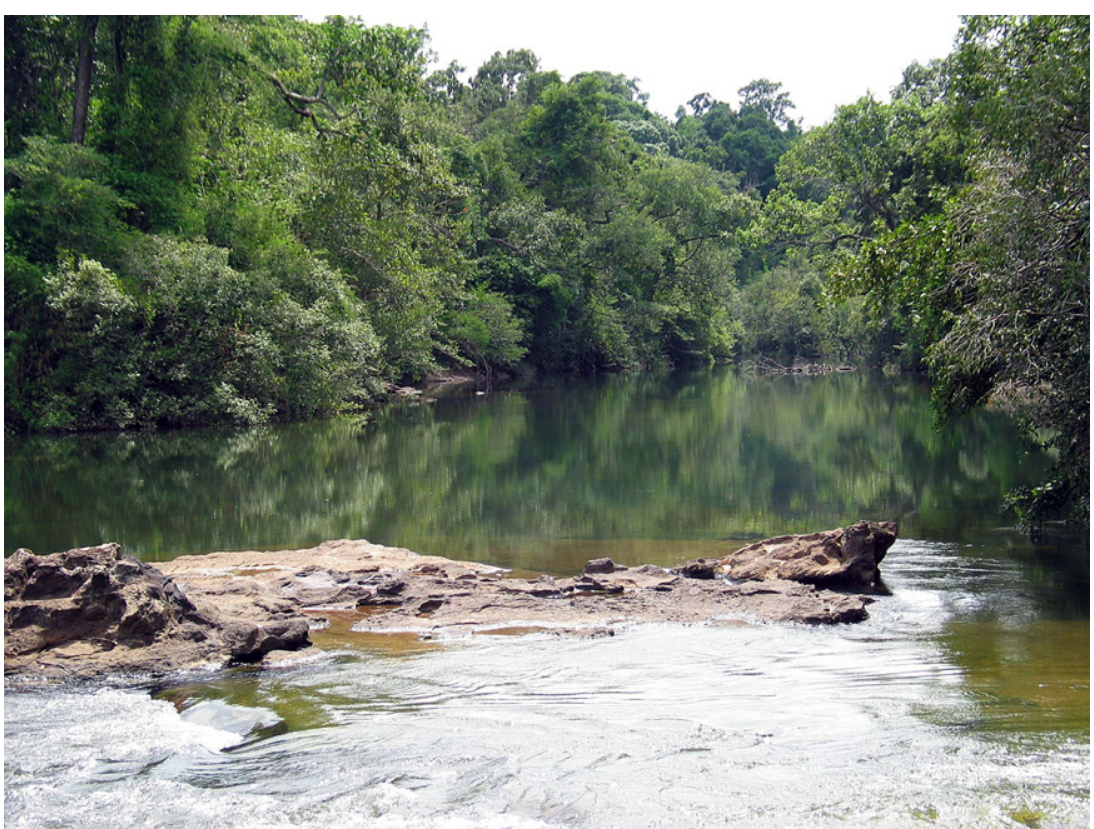

Fig. 8. Typical referent of the Lao word vang2: river pool, deep water, not perceptibly flowing, towering forest, spooky, inhabited by spirits.

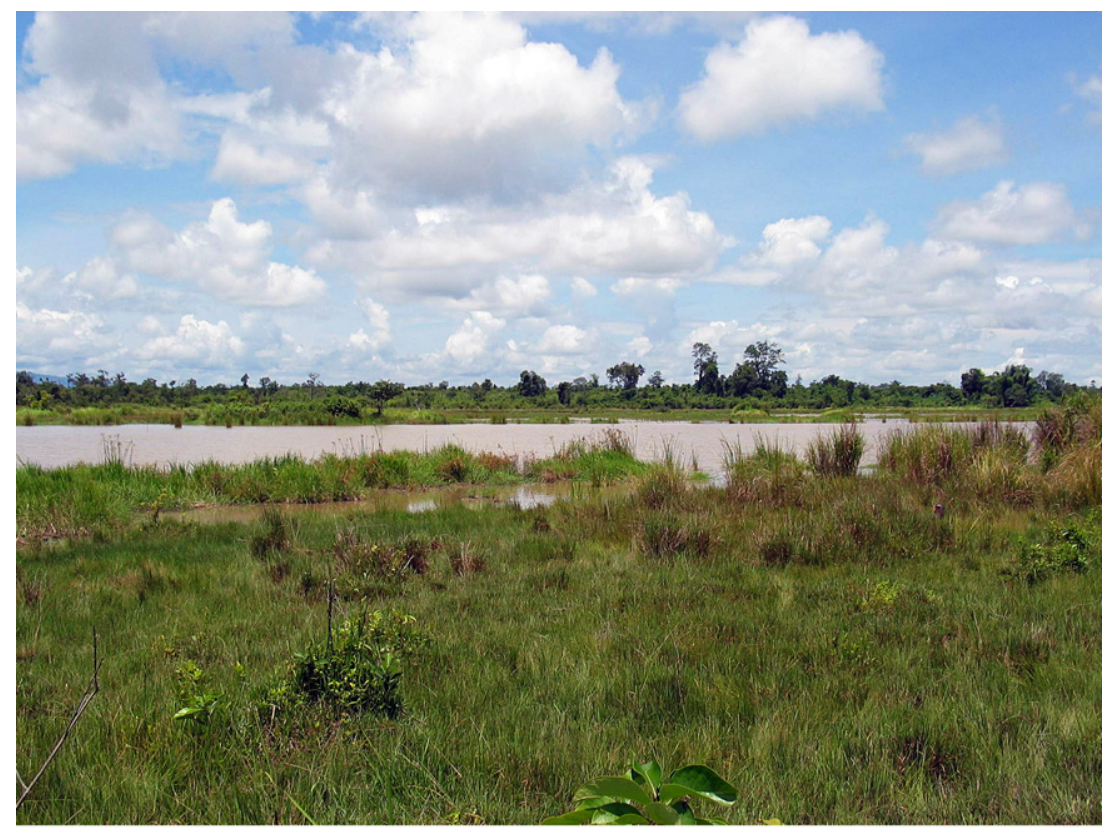

Fig. 9. Geographic detail corresponding to the Lao words bùng3 and nò̀ng3, Vientiane Plain, Laos. 


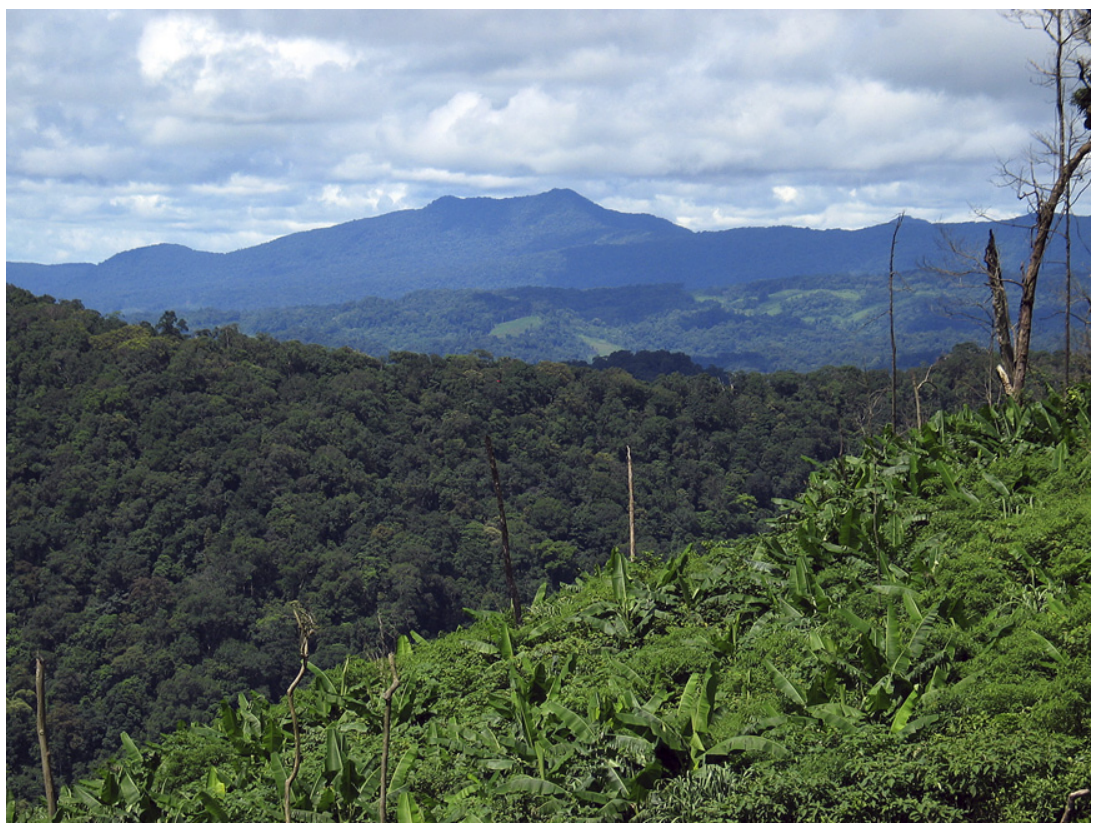

Fig. 10. Typical referent of the Lao word phuu2 'mountainous terrain'.

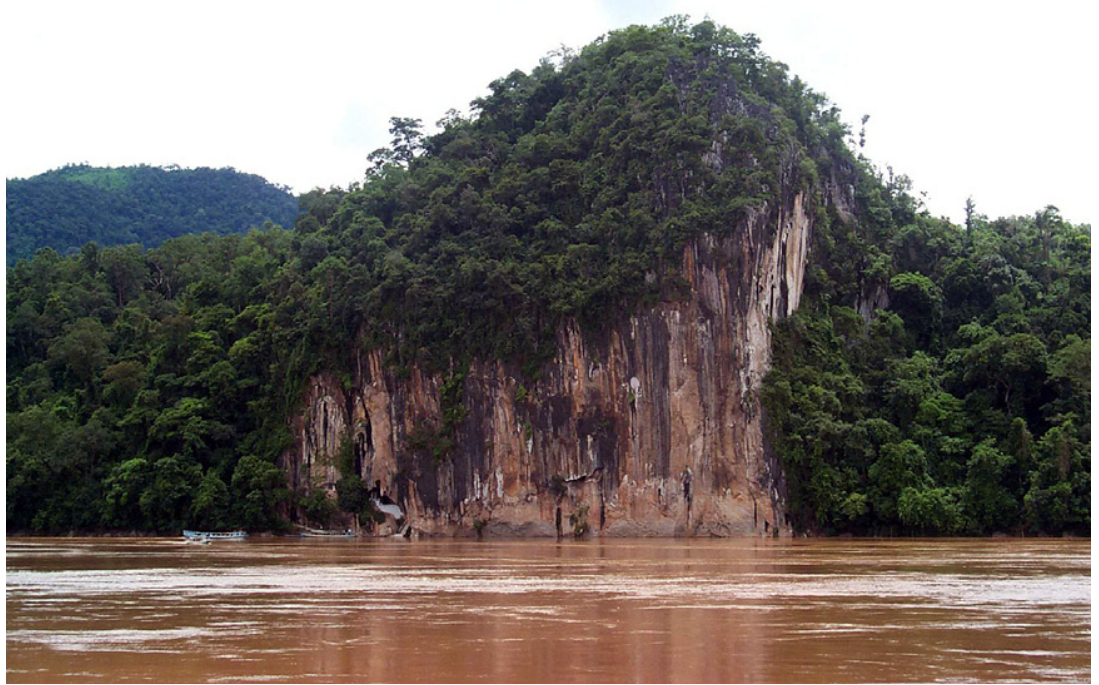

Fig. 11. Typical referent of the Lao word phaa3 'vertical exposed rock face'.

is often translatable as 'cliff', but is more accurately glossed as 'vertical exposed rock face', as illustrated in Fig. 11. 


\subsection{Forest/vegetation type}

The word paal is often translatable as 'forest', but it refers more generally to any large area of naturally occurring vegetation: a place where people do not live, and where local vegetation grows unchecked. Accordingly, 'wildlife' is referred to as sat2 paal 'animals of paal'. The reference of paal is broader than any comparable English word, and its referents may be variously referred to in English as forest, jungle, scrub, or bush.

At a narrower level of specificity, there are terms referring to sub-types of paal. Let us compare two common types, khook4 'spaced, dry, open forest' and dong3 'jungle; thick, dense, dark, cool forest' (see Figs. 12 and 13).

These two types of natural environment are linked in the Lao imagination to a range of conceptual associations, as well as potential transformations for human livelihood activity. Khook4 is normally flat, conceived of as relatively easy to travel through by walking, open to sunlight, dry, often without very tall trees. Particular kinds of plants and animals are hunted and collected in khook4 - salient examples (i.e. which informants will readily supply) are mushrooms, lizards and certain types of insects. Khook4 is transformed by people into paddy (see Fig. 14).

By contrast, dong3 'jungle' is conceived of as difficult to travel through, untidy and steep, damp, dark and cool under a high canopy with tall trees. Particular kinds of plants and animals are hunted and collected in dong 3 - salient examples being forest plants such as rattan, and mammalian wildlife such as gibbons, wild pigs, civet cats, leopards and pangolins. Dong3 is transformed by people into haj1 'swidden fields' (see Fig. 15).

Further terms for forest/vegetation/ground type in Lao include thongl 'naturally occurring open treeless expanse', deen1 'man-made clearing', and daan3 'natural stone clearing'.

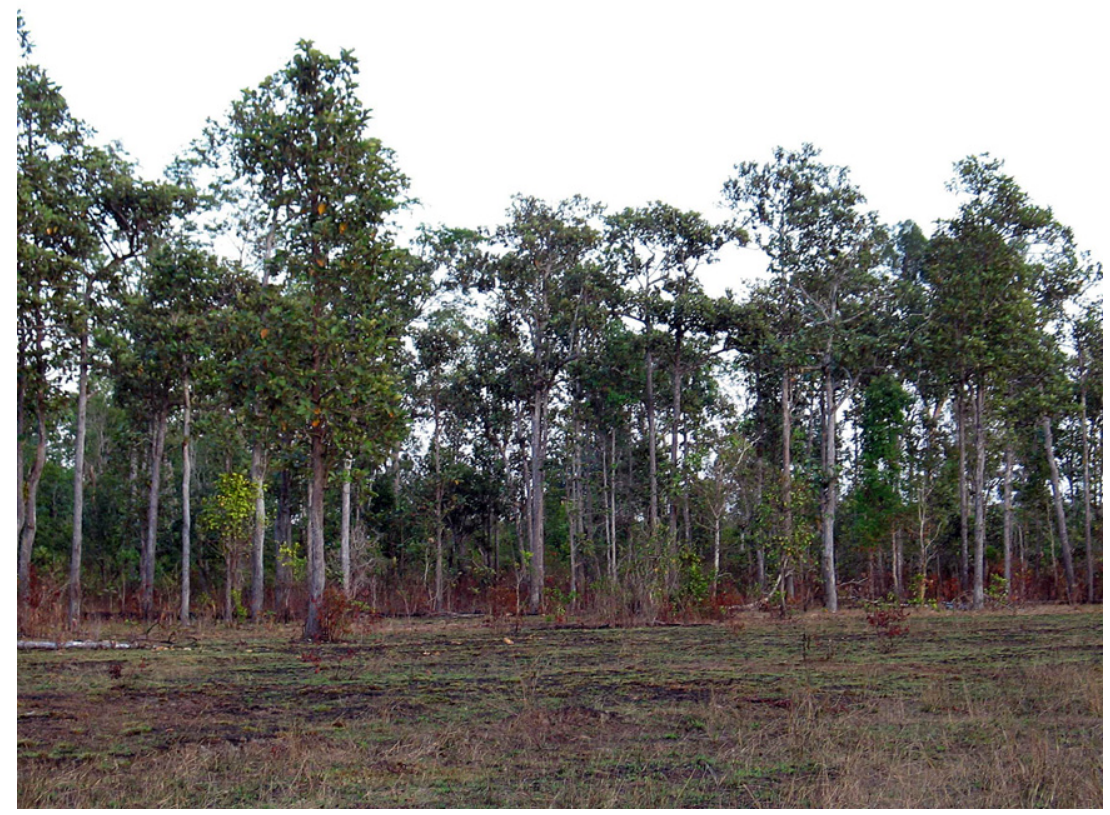

Fig. 12. Typical referent of the Lao word (paal) khook4 'spaced, dry, open forest'. 
a

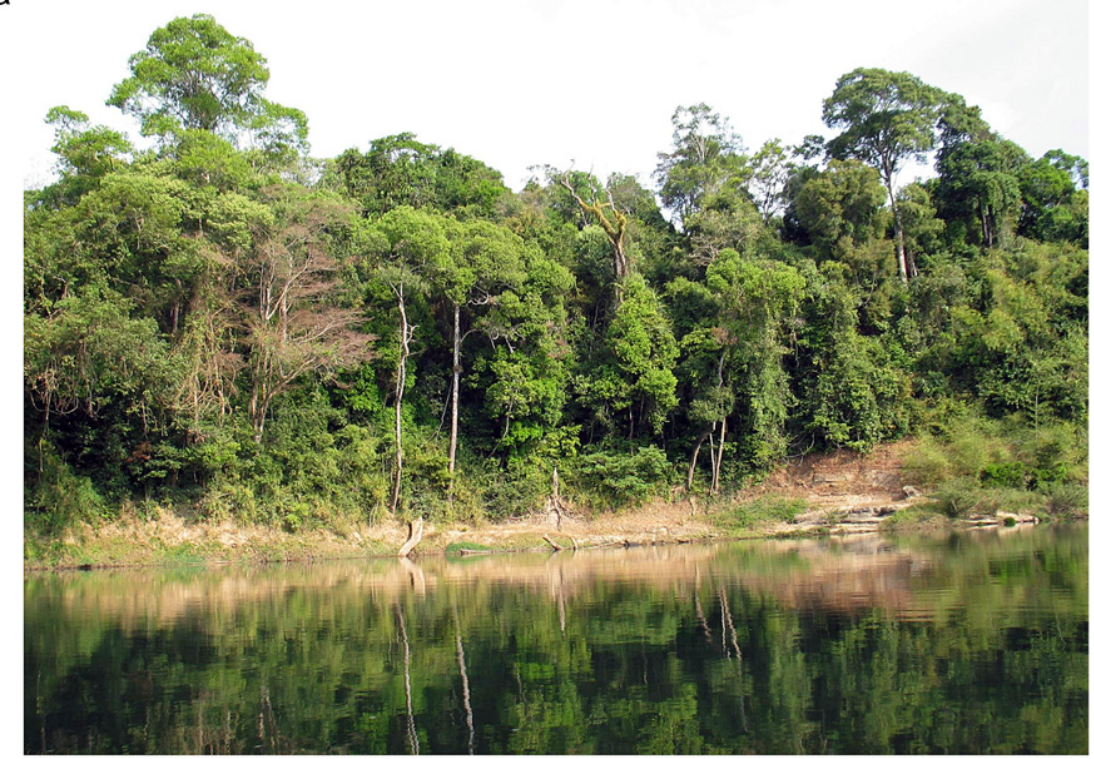

b

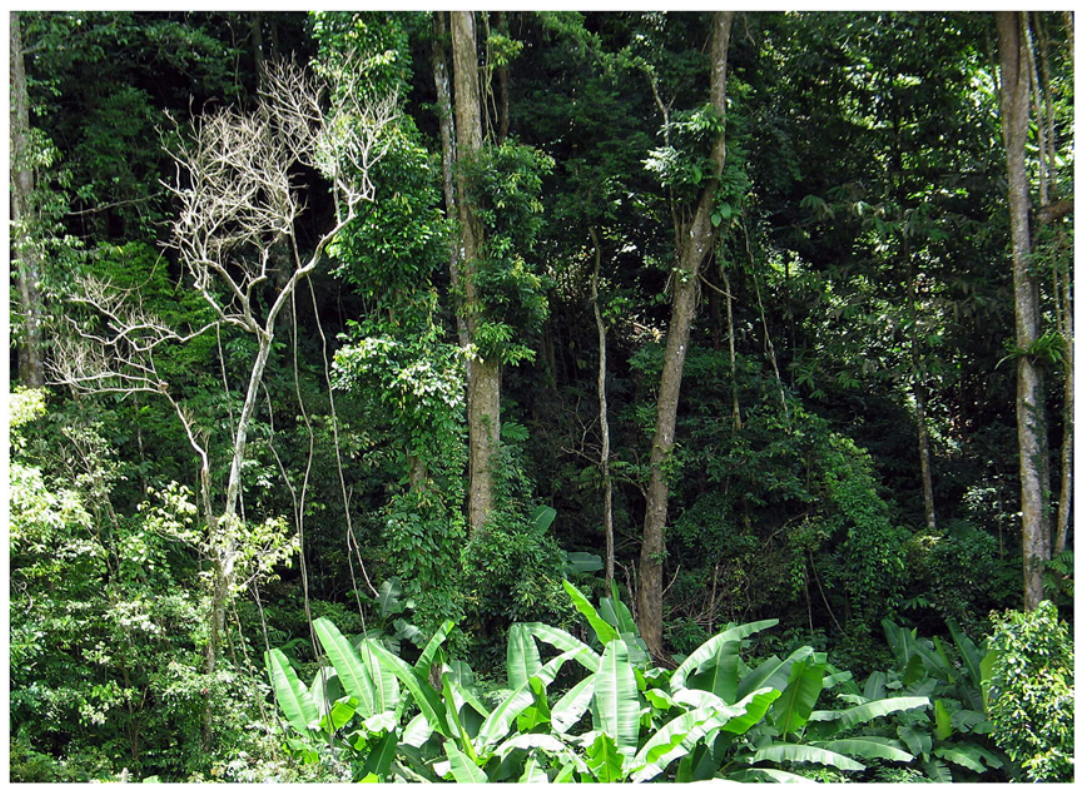

Fig. 13. Typical referents of the Lao word (paal) dong3 'jungle; thick, dense, dark, cool forest'.

\section{The logic of linguistic categories}

Armed now with a sketch of the Lao speaker's inventory of terms for description of the landscape, we delve into the theoretical question: How do speakers of Lao come to know the meanings of these words, and the range of things they may refer to? Roger Brown proposed that LINGUISTIC USAGE is the word learner's primary supplier of data for constructing 


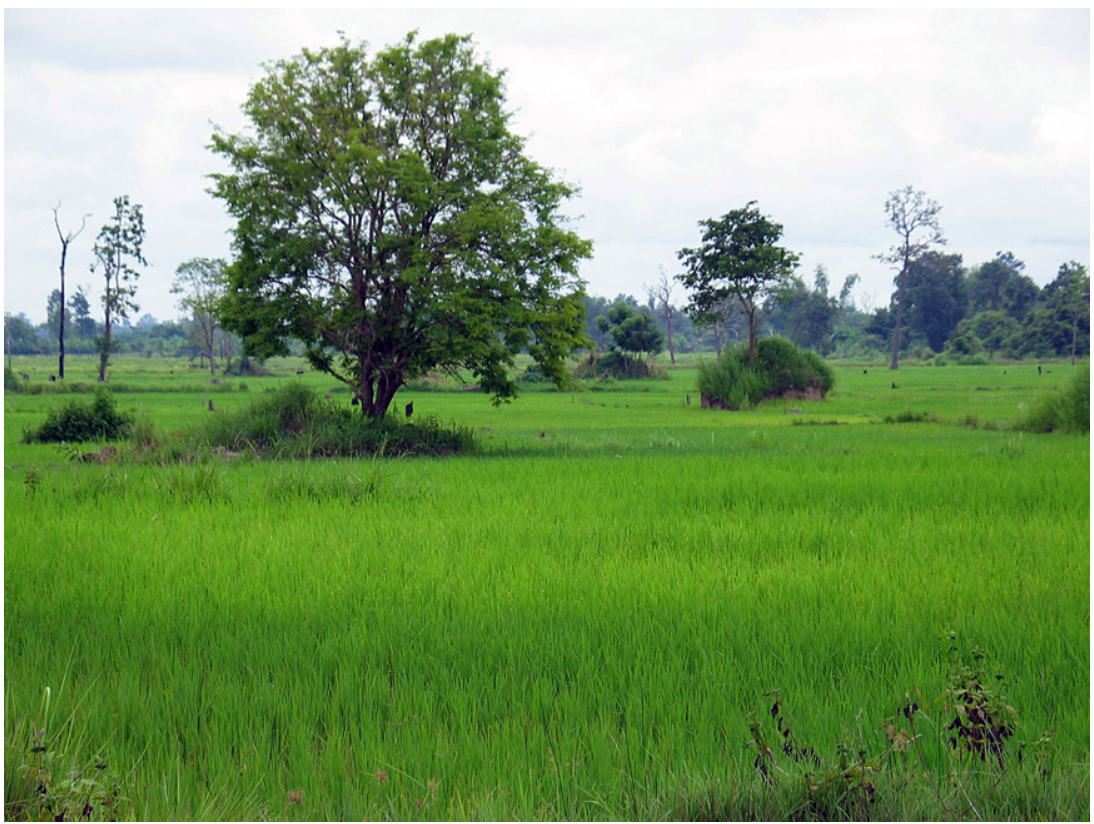

Fig. 14. Paddy field (naa2), formerly khook4 'spaced, dry, open forest'.

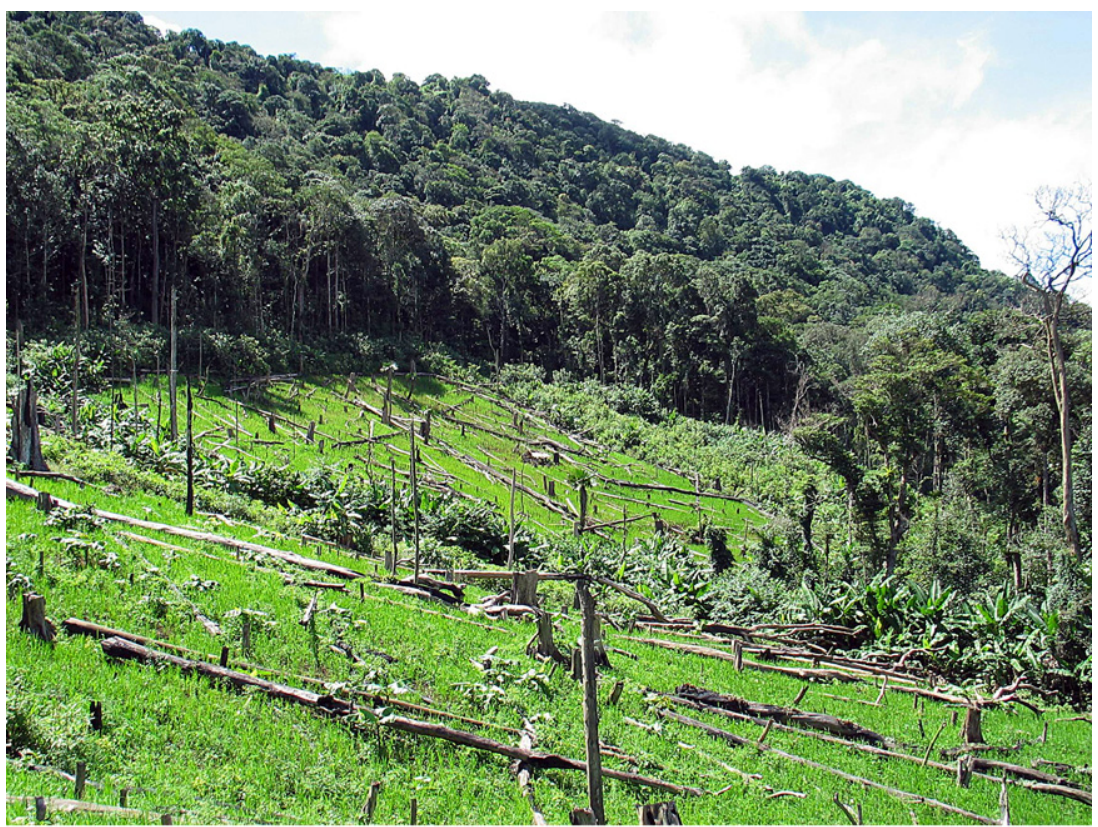

Fig. 15. Swidden fields (haj1), formerly dong3 'jungle; thick, dense, dark, cool forest'. (Here, dong3 is visible behind the new swidden.) 
hypotheses of word meaning. Perceptual impressions of a word's referent are secondary (Brown, 1958, p. 208). My aim in the rest of this article is to pursue an argument in favor of this position, which may be described as the word utility hypothesis, using as our point of empirical illustration examples from the Lao landscape vocabulary.

\subsection{The utility of words and their meanings}

Clearly, word meaning involves categorization. The question is: What defines the psychological basis of a linguistic category? Let us take as a point of focus the intellectualist versus utilitarian debate within research on linguistic categorization in the biological domain. Berlin (1992) argues that patterns of lexicalization in biological classification are driven by human beings' innate intellectual interest in the natural world, in direct combination with structure supplied by perceptual discontinuities in nature, in interaction with the human perceptual apparatus. By contrast, the utilitarian position (e.g. Hunn, 1982, 1985) holds that lexical distinctions will reflect the affordances of referents for the communities who use the languages. The claim is that communities will linguistically recognize those categories of entity which are of practical importance to members.

I am going to argue for a utilitarian view, but it is not the one that Berlin undermines in his 1992 book. The debate applies to categories in general rather than directly to LINGUISTIC categories. When we consider carefully the nature of linguistic categories, the picture changes. Words are double categories: they feature signifiers or word-forms, on the one hand, and signifieds or referents on the other. A word-form category stands for a meaning category (Saussure, 1916). By word-form I mean the conventional 'sign' material that labels the word (e.g. the sound of the word when spoken, or the visual image of the word when signed or when written). In the rest of this article, when I use the expression 'word', I intend 'word-form', i.e. the (public) signifier component of the linguistic sign. By referent, I mean, primarily, the (private) concept or idea that the word form stands for (i.e. the 'sense' of the word; Frege, 1892). I will also allow the term referent to denote an actual thing in the world that the word is understood to refer to (Frege's 'reference') - e.g. any of the features photographed in the Figures. I shall allow this vagueness, i.e. between sense and reference, unless I need to be specific.

While REFERENTS of words may or may not have utility for people, their word-forms (i.e. the phonological or graphic 'referents' of words) MUST have utility. If a feature of the natural world ceased to be of use or interest to humans, this lack of human interest would not cause that natural feature to cease to exist. But if a wORD referring to such a feature ceased to be of use or interest to humans, then the word certainly would cease to exist. ${ }^{2}$ As cultural entities, words depend for their existence on circulation and reproduction within the community (Sperber, 1985; Enfield, 2003, 2005). So, we must ask as to THE UTILITY OF THE WORD ITSELF. An innate intellectual interest in perceptually salient distinctions in nature is insufficient to affect language. The intellectual interest cannot be effective in the way Berlin describes if it remains in the individual's mind. To enter into linguistic structure, this intellectual interest has to be made public, it has to be a shared

\footnotetext{
${ }^{2}$ Some of the world's languages may be written in semi-permanent form (in books, palm-leaf manuscripts, stone inscriptions), and this can significantly improve the chances that a word-form will not truly die out in the short term if it is not used by people in daily life. Most languages, however, do not have written forms. This means that if a couple of generations pass without a certain word being spoken, the word is gone.
} 
focus of social interaction. An individual who forms conceptual categories based on perception and innate curiosity need not label them with words.

This raises the empirical question, so far not raised in the utilitarianist versus intellectualist debate: what are the wORDs good for? An obvious answer is that words are good for saying things. An effect of their utility in this sense is that they can guide both language learners and analysts to their content by the ways in which they are contextually deployed. For us to understand word meaning, our experience with a word in its communicative context is more important than our experience with worldly referents of the word. What we hear people say about things gives us clues about the supposed properties of those things (Clark, 1999), many of which are not directly retrievable from, or rendered especially salient by, visual or other perceptual impressions. In linguistic analysis, this means we must turn to corpus data (including conversation and collocations) as evidence. We now consider why I think this has to be.

\subsection{Categories are purpose-defined, imposed}

To categorize is to treat as alike some set of phenomena based upon some criterion, for some purpose. For instance, when I categorize various orthographic symbols as "the letter R", I am treating them alike, even though they are formally distinct:

(1) $\mathrm{R}, \mathrm{R}, \mathrm{r}, r, \ldots$

To categorize these marks as the same is to treat them as alike or equivalent for some purpose, say for writing the word river (RIVER, RIVER, river). In this sense, the category is PURPOSE-DEFINED. For the purpose of writing the word river, the differences between the symbols in (1) do not make a difference (as Bateson, 1972, p. 453, put it, information is 'a difference which makes a difference'). But for another purpose, the difference DoEs matter. For instance, ' $r$ ' will not do as the first letter of a proper name, or of a sentence. The forms listed in (1) are not identical. It is only for particular purposes that we treat them as such.

Consider the purpose-defined nature of categories in the landscape domain. (To be clear: I am talking about categories, not yet about LINGUISTIC categories.) Many rural Lao speakers practice a wide range of fishing techniques, involving dozens of different forms of traps, lines, nets, and other devices (Claridge et al., 1997; Enfield, 2004b). Each fishing device is appropriate for a different range of aquatic environments depending on its design and manner of deployment. Any accustomed practitioner of these fishing techniques will be able to categorize the aquatic environment based on these practices. For instance, a range of non-identical physical environments will be defined by patterns of human behavior as alike with respect to their suitability as places where one may fish using a hèe 'cast net' (Claridge et al., 1997, p. 19) (see Fig. 16 and 17).

These two otherwise rather different looking pieces of geographical reality are functionally equivalent with respect to their suitability for fishing using a hèe. The circular net is used in shallow, gently flowing water. It is cast out over the water such that it is fully unfurled when it lands on the water's surface (visible in Fig. 16). When its lead-weighted outer edge causes its perimeter to sink quickly, any fish which happen to be directly underneath the net when it lands become trapped. He who non-randomly selects among environments for fishing with a hèe 'cast net' will, by virtue of this selection behavior, have a categorial representation of 'places where one can go fishing using a hèe', defined, in 


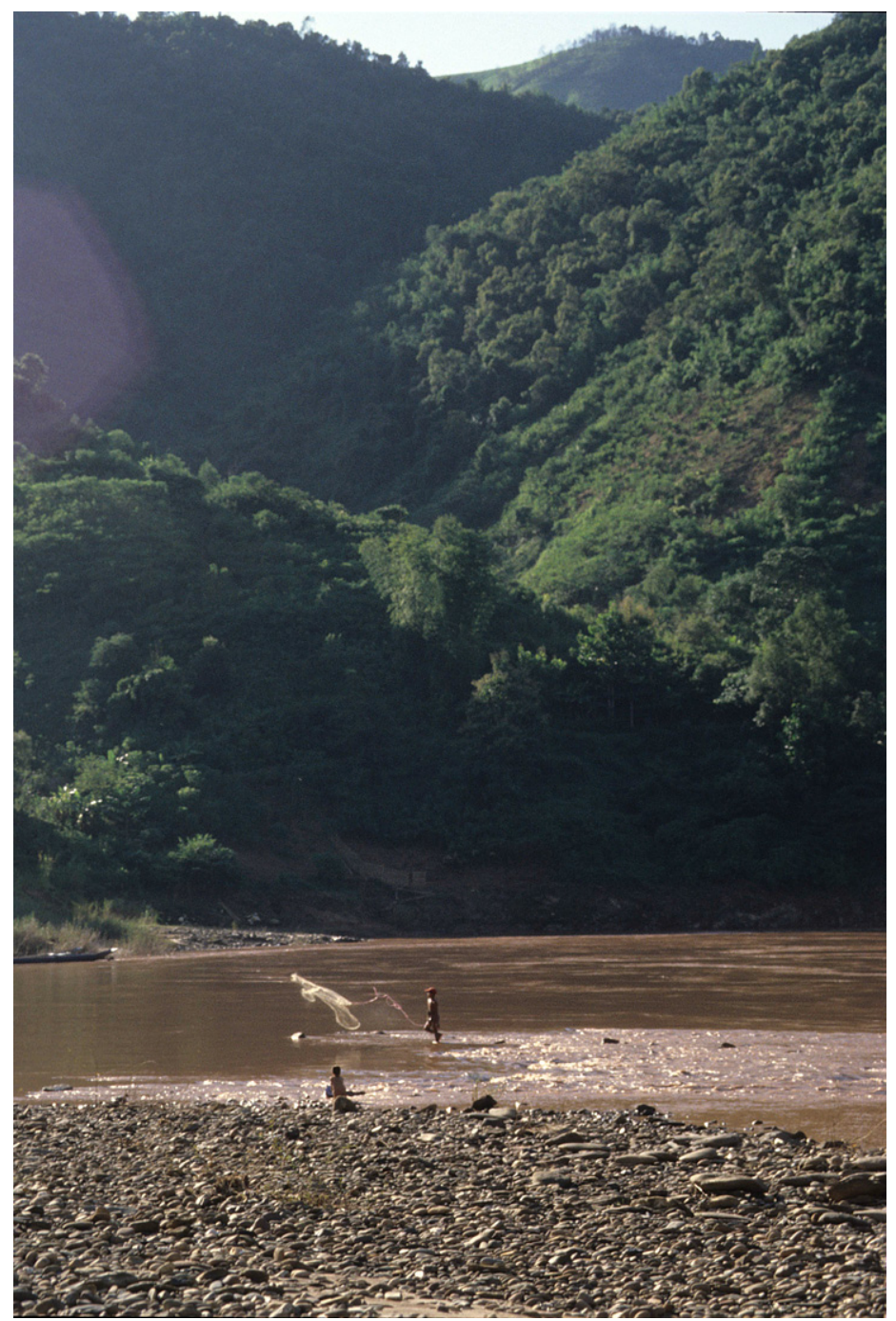

Fig. 16. Casting a hè 'cast net' in a shallow stretch of river.

part, by the depth (not more than waist-deep) and flow (not strong) of water. This category does not have a simple linguistic label, and in that sense may seem similar to Barsalou's (1983) 'ad hoc' categories. Barsalou's ad hoc categories appear not to have been independently represented before experimental subjects required them in order to solve the ad hoc tasks they were given - for instance, listing ways to escape being killed by the mafia. But for the user of a hè fish net there is prima facie evidence that a category along the lines of 'places where one can go fishing using a hè it not having a simple label: the evidence is the fisherman's capacity to select appropriate locations when going fishing with a hè in places they have never been before. In the same way that the unalike symbols " $\mathrm{R}$ " and " $\mathrm{r}$ " are treated alike for some purposes, and una- 


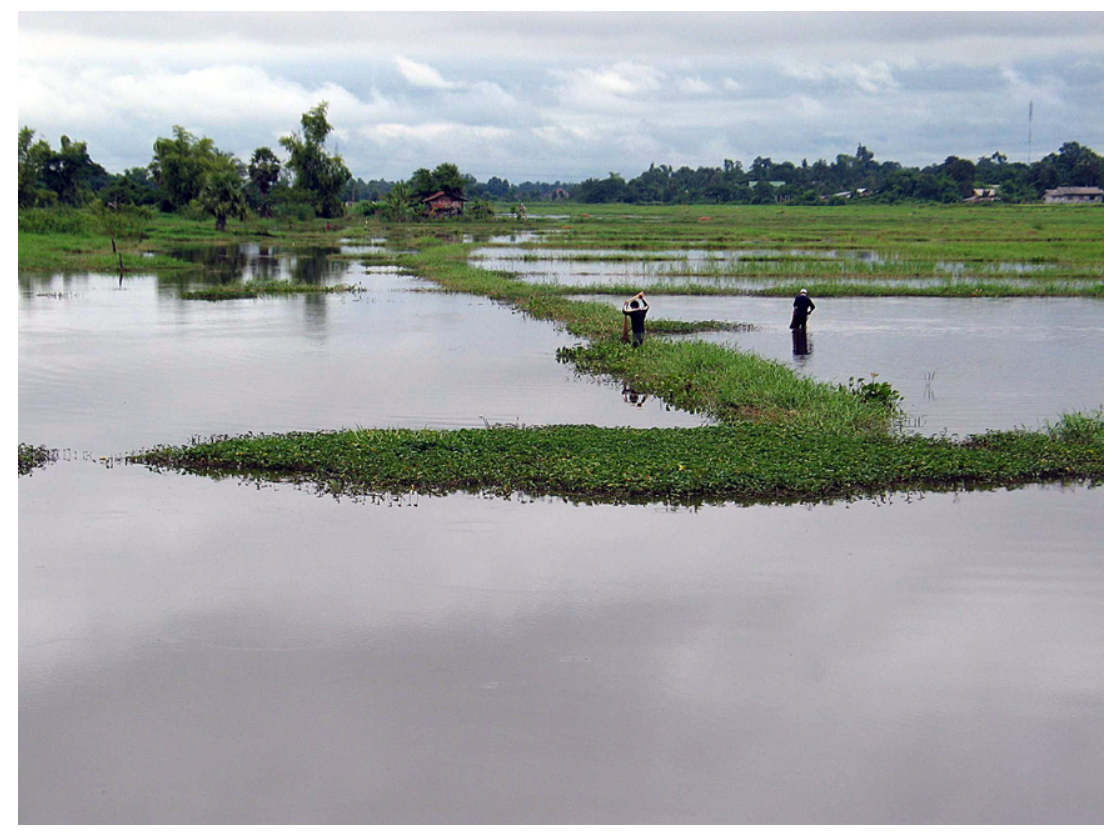

Fig. 17. Preparing to cast hèe 'cast nets' in a flooded paddy field.

like for others, a Lao-speaking fisherman will treat rather disparate features of the landscape as alike - i.e. grouping them in a single category - for certain purposes and not for others.

A Lao fisherman will categorically distinguish the class of hèe-useful environments exemplified in Figs. 16 and 17 from other kinds of physical environments defined by their suitability for other kinds of fishing devices. For example, using a toum thoong 'giant upright basket trap' requires deep water at the banks of the largest rivers (see Fig. 18).

These examples illustrate a cultural rationale for categorizing the landscape. The different water features show differential utility as determined by a suite of affordance properties, including the design of different fishing devices, human access to different aquatic environments, and presence of certain target types of aquatic life. More broadly, the very wide range of cultural activities which entail direct interaction with the geographical environment result in a richly culture-specific understanding of the landscape. It is a rich ethnography of the landscape, waiting to be done.

\subsection{Two types of utility in categorization}

The discussion so far suggests two types of utility in categorization. One type may be called category-utility. Derived from psychological structures which serve to draw our attention away from differences and regard literally unalike things as alike, all categories exist for some purpose. They are employed in strategically generalizing about the structure of the world. A Lao fisherman's category of 'places where I can go fishing using a hèe' functions to identify actual places which fit the description, allowing them to be treated alike for the purpose of deciding to grab a cast net and go out fishing. 


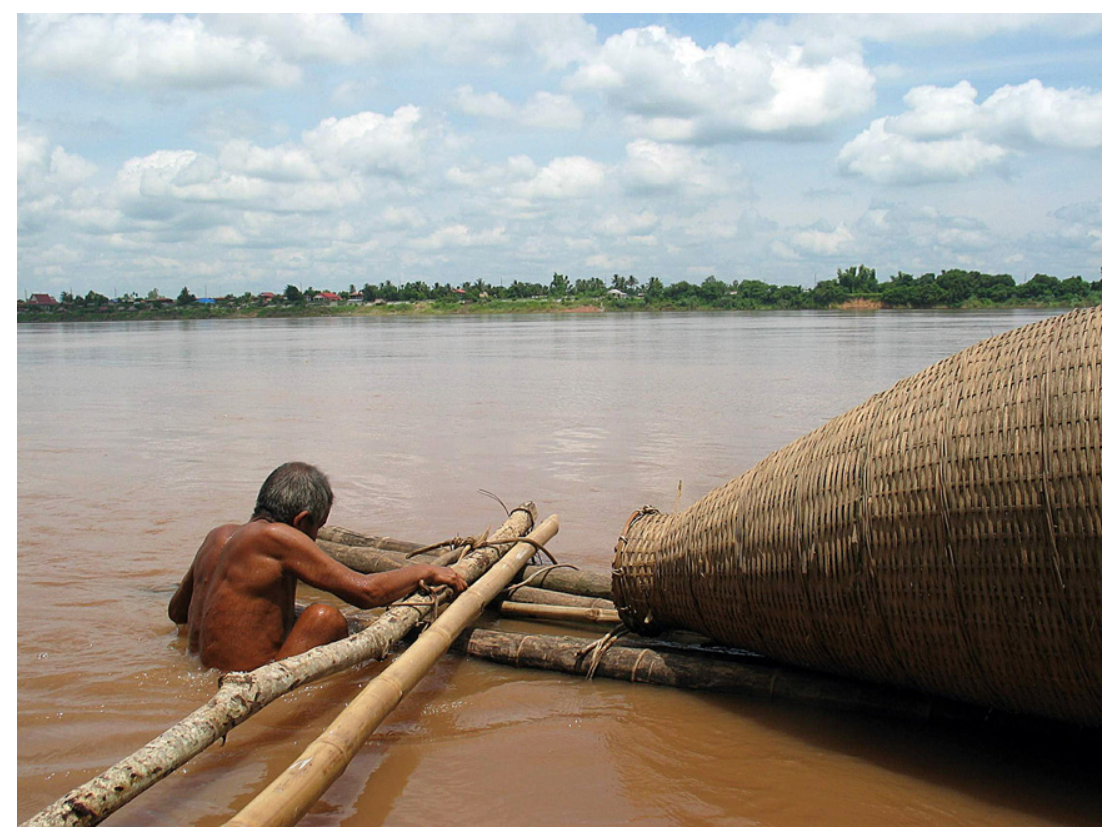

Fig. 18. Preparing to place a toum thoong 'giant upright basket trap' in deep water at the bank of the Mekong river (Vientiane Plain, Laos).

A second type of utility a category may have is referent-utility. For some but presumably not all categories, the defining rationale for grouping a set of real world phenomena may be their conceived utility for the categorizer. ${ }^{3}$ The notion of utility fits within a broader notion of a category's COGNITIVE CONTENT (Prinz, 2002, p. 7, Chapter 10) or its INTERNAL LOGIC (Wierzbicka, 1985, p. 19). 'Places where I can go fishing using a hè 's states a category's cognitive content or internal logic in the same way as for functionally defined categories (e.g. English toy, weapon, furniture; cf. Wierzbicka, 1984) or ad hoc categories (e.g. ways to escape being killed by the mafia, things not to eat on a diet, restaurants to watch a sunset in; Barsalou, 1983). There are, however, many types of category whose referents have no obvious function or affordance for the categorizer (Berlin, 1992, pp. 183190). Take the category referred to by the Lao word thalêe 2 'sea'. Most Lao speakers have never set eyes on the sea, not even in a photograph. They do, however, have a conceptual category denoted by the word thalêe 2 , with some degree of cognitive content. Lao speakers will have formed a concept of 'sea' not because they have encountered any worldly referent of the word, but because they have encountered the word itself. This points us now to the special properties of linguistic categories.

\footnotetext{
${ }^{3}$ This is related to Gibson's notion of affordances (Gibson, 1979). The idea combines perception/form and function in one, via Peircean indexicality. See Kockelman (2006) for a careful explication of the semiotics of affordances and related aspects of the 'residential whole'.
} 


\subsection{Words are double categories, with multiple utilities}

So far I have been talking about categories as the product of private psychological structures. LINGUISTIC categories are more than this. Linguistic categorization is more complex than mere categorization because it involves the public constitution of categories (the consequences of which are surprisingly underappreciated in prominent work on concepts and categories: Fodor, 1998; Murphy, 2002; Prinz, 2002; Taylor, 1989). Linguistic categories are special because they are double categories. Take as an example the Lao word vang2, described above in Section 2.2 as a river pool, with deep water, not perceptibly flowing, with towering forest around it, spooky, and inhabited by spirits. Like any other linguistic category, vang2 combines (at least) Two constituent categories - a semantic category and a phonological category, linked by a symbolic function (cf. Langacker, 1987, pp. $11 \mathrm{ff}$; this is as Saussure depicted it). ${ }^{4}$ Each of these is a category in its own right, with (potentially) two utilities of its own (see previous Section 3.3). Each has category-utility, enabling or causing our disattention to differences between single instances, leading us to treat them as tokens of types. So, a Lao speaker's use of semantic categories will enable her to regard or recognize two different river pools as instances of the same thing: a 'vang2'. And her use of phonological categories (as word-forms or signifiers) will enable her to regard two different pronunciations of the word-form vang2 as instances of the same thing: the word vang2. In addition, each of the two constituent categories of vang 2 - the semantic and the phonological - have referent-utility. There is a host of things a 'river pool' affords, including easy boat travel in any direction (thanks to deep, open water, with minimal flow), certain types of tree, certain kinds of herbs, aquatic life, etc. A Lao speaker's concept of 'river pool', as denoted by vang2, will specify what any vang2 'river pool' should normally be presumed to be good for (even if any specific vang2 turns out to have other properties), and beyond this she may ignore details (e.g. whether it is 3 miles long or $100 \mathrm{ft}$ long, whether it is kidney-shaped or circular). In addition, she may have generic perceptual representations of a vang2, for instance what it should look like.

Most important for our current purpose of illustrating what is special about LINGUISTIC categories, THE WORD vang2 (i.e. the phonological referent indexed by the phonetic string) also has utility. It can be used to say things to people (i.e. about the things we label as vang2). And of course Lao speakers do not randomly say things about things, but by making such references they are coordinating with others in order to carry out actions in social interaction (Stivers et al., 2007). This is because the word is primarily not for 'representation', but is a device for social coordination, à la Schelling (1960; cf. Barr, 2004; Clark, 1992, 1996a,b; Levinson, 1995; Lewis, 1969; Schiffer, 1972; Grice, 1989). Words exist first and foremost in the service of doing things socially, whether it be planning a fishing trip, describing where mushrooms can be found, collaborating in building a house, telling a joke, getting money from someone, complaining about someone's bad behavior,

\footnotetext{
${ }^{4}$ This is a simplification. Even in a Saussurean version, the linguistic sign has more than two components. In the original model (Saussure, 1916), there are three components if we include the 'relation of correspondence' standardly diagrammed with up-and-down arrows. There are four components if we also include the sign's 'combinatoric' properties within the larger sign system (Evans, in press). In any case, all these versions of the sign are too static, lacking the interpretative dimension offered by Peirce (1932) and elaborated by neo-Peirceans like Kockelman (2005).
} 
bragging in order to better one's own reputation, persuading someone to come along, or whatever (cf. Atkinson and Heritage, 1984; Dunbar, 1996).

If a word like vang2 'river pool' is a category for a Lao speaker, what does he or she Do with this word? In the first instance, word usage patterns constitute word learners' basis for constructing semantic hypotheses, which go on to become the (effectively) fixed and conventional semantic representations which linguists are in the business of describing. Eve Clark shows how adults systematically design linguistic contexts for children which provide them with pragmatic evidence for the construction of word meaning. She shows how adults' linguistically contextualized use of words helps children, as word learners, to identify new words, to establish ways in which the meanings of those words contrast with other words, and to establish ways in which the referents of those words are connected with the referents of other words. In short, "children learn words from observing how they are used in everyday conversations with the people around them" (Clark, 1999, p. 4). This informal tutoring is what Roger Brown dubbed the "original word game" (Brown, 1958, Chapter 6). The word learner is tutored by experts, forming hypotheses as to word meaning, and subsequently testing these hypotheses against further encounters. And the role of discourse as a (public) source of focus for (private) representations of linguistic meaning is not confined to early word learning. This point is of special relevance to our discussion of the semantics of landscape terms in adult language. As Brown put it, "We play this game as long as we continue to extend our vocabularies and that may be as long as we live" (Brown, 1958, p. 194). I now want to briefly illustrate this point by showing the kinds of things Lao speakers actually say when they use words like nòng 3 'swamp', vang2 'river pool', or phuu2 'mountainous terrain' in social interaction.

\section{Landscape terms in use}

Let us now tie the previous section's theoretical discussion of linguistic categories back to the uniquely Lao landscape categories described in Section 2. We consider evidence from (video) recordings in which references to the landscape are made in the course of normal conversation. These examples illustrate the most important kind of data we have for determining the utility of linguistic categories, i.e. natural usage. By looking at words in their natural environment, we see first what people actually use them for, and second, we see in their contexts of use many important clues as to their semantic contents.

\subsection{Nò̀ng3 'swamp, marsh' as source of reeds for mat-weaving}

A Lao speaker makes spontaneous reference to the water feature nò̀ng3 'swamp, marsh' (Fig. 9, above), in the course of natural conversation: ${ }^{5}$

$$
\begin{array}{llll}
\text { phùu̇ } & \text { nò̀ng3 } & \operatorname{lom} 2 & \text { khèèng3 }+ \text { khèèng3 } \\
\text { reed } & \text { swamp } & \mathrm{L} & \text { tough }+ \text { tough } \\
\text { 'Reeds (from) Lom } \text { swamp are really tough.' (ref. 030806k_0403) }
\end{array}
$$

\footnotetext{
5 Abbreviations used in examples: capital initial letter for gloss of proper name; $\mathrm{pcl}=$ particle; $3=$ third person; $\mathrm{pl}=$ plural; $\mathrm{f}=$ female; prf $\mathrm{x}=$ prefix; neg = negation; tpc $=$ topic. Code numbers after examples refer to the original data source.
} 
The speaker is engaged in preparation for making reed mats, as illustrated in Fig. 19.

This spontaneous use of the word nò̀ng 3 'swamp, marsh' comes in a context which makes explicit one of the characteristic properties of a nòng 3 , namely that it is a source of at least one type of reed (in this case, phùu 3 'Cyperacea sp.'). Correspondingly, if that same type of reed is mentioned in conversation, it evokes in turn the notion of noòng3, the landscape feature where it may be found. Here is an example from a different recording, this time between two men, in which a speaker uses the word phùu 3 'reed (Cyperacea sp.)' in answering a 'where?' question:

\section{Q}

$$
\begin{aligned}
& \text { qi0 + qòj4 paj3 saj3 han0 } \\
& \text { f.prfx + Q. go where pcl } \\
& \text { 'Where did Miss Oi go?' }
\end{aligned}
$$

A paj3 bengl khaw3 qaw3 phùù han0

go look $3 \mathrm{pl}$ take reed $\mathrm{pcl}$

'To look at them collecting reeds.' (ref. 030806a_0730)

I took the source video recording of this utterance and played it to several Lao-speaking informants, on separate occasions. When I asked them about the likely whereabouts of Miss Oi, they consistently replied that she must have gone to a nòng3 'swamp, marsh' (or a bùng3). This is consistent with the claim that part of one's knowledge of the meaning of nòng 3 is that it is a place where one would go to collect reeds. This is what underlies the inference which may be made from (3). The explication of this connection in (2) is not only evidence of the conceptual and cultural association of the reeds and this kind

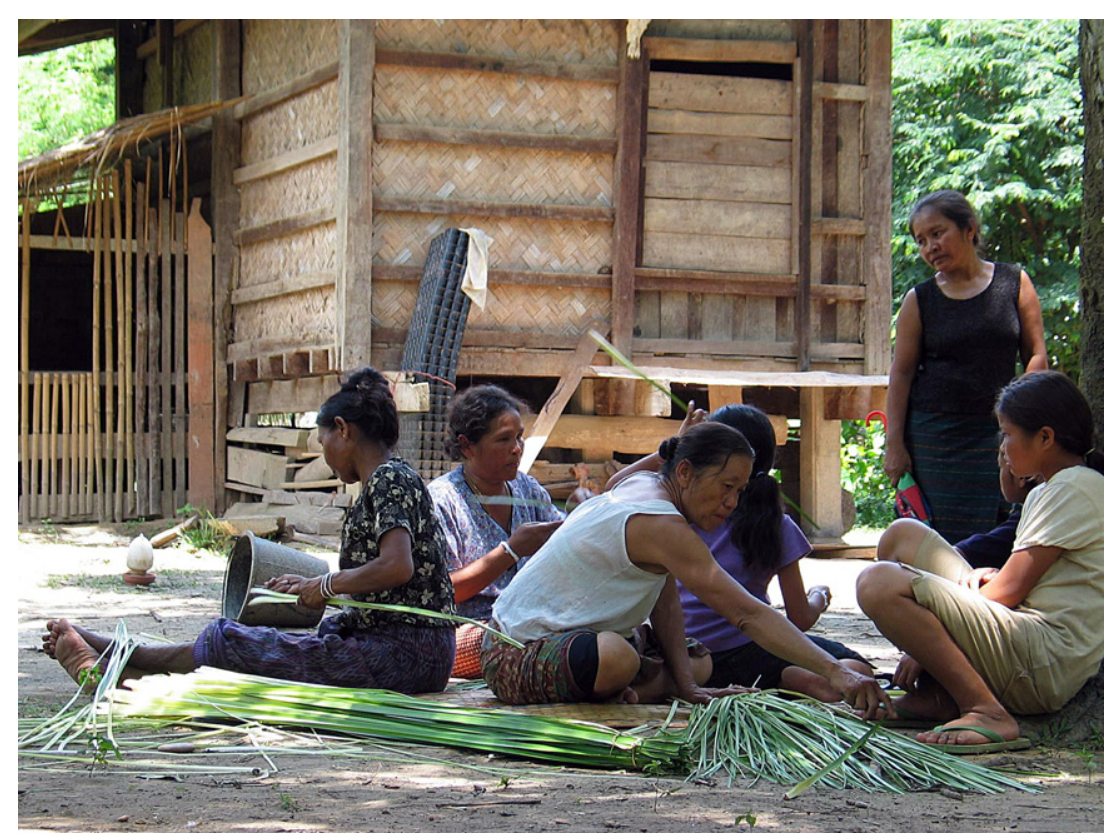

Fig. 19. Preparing phùù reeds for mat-weaving, Vientiane Plain. 
of landscape feature, it is also what helps to publicly display, and thereby teach and perpetuate that association.

\subsection{Vang2 'river pool' as source of medicinal plants, and as home of local spirits}

In the next example, a speaker makes spontaneous reference to a vang2 'river pool' (Fig. 8) in the local area, as he discusses the source of a medicinal plant called khiingkhaj-ton:

$$
\begin{array}{lllllll}
\text { khiing3-khaj2-ton4 } & \text { la0 juul thèè3 vang2 } & \text { phêêng2 phun0 la0 } \\
\mathrm{K} & \mathrm{pcl} & \mathrm{be} \text { at area } & \text { river_pool } \mathrm{P} & \mathrm{pcl} & \mathrm{pcl}
\end{array}
$$
'Khiing-khaj-ton is (found) over there at the area of Phêêng river pool.' (ref. 020727_0558)

The utterance explicitly associates the landscape feature vang2 'river pool' with its role as a source of this particular kind of medicinal plant, not only revealing the association to us as analysts, but also revealing it to his social associates and thereby contributing to its conventionalization at some level in the word's semantics. A vang2 is, thus, in part, 'the kind of place where one may find khiing-khaj-ton'.

Another example of the word vang2 'river pool' in spontaneous conversation reveals a different kind of information encoded in its semantics: the idea that these overgrown, spooky, deep water features are typically inhabited by local spirits which need to be appeased by villagers when accessing resources or traveling through. This next conversational extract follows on from the previous, after some discussion of the difficulties of extracting medicinal plants from a local vang 2 whose proper name is Phêeng. These difficulties are attributed to the 'seriousness' of the local spirit:

$\begin{array}{llllllll}\text { (5) bò̀1 mè̀n1 } & \text { lin5 + lin5 } & \text { dêj2, } & \text { phii3 } & \text { vang2 } & \text { phêêng2 } & \text { ni0 } \\ \text { neg } & \text { be } & \text { play }+ \text { play } & \text { pcl } & \text { spirit } & \text { river_pool } & \mathrm{P} & \text { tpc.pcl }\end{array}$

'It's not joking around you know, the spirit of Phêeng river pool.' (ref. 020727_0720)

Here, the speaker explicitly links the notion of vang2 'river pool' to the presence of spirits, in the first explicit mention of spirits in this stretch of conversation (cf. Enfield, 2006b, pp. 419-422), for more detailed discussion of this example.

Examples (2-5) demonstrate the spontaneous, explicit association of types of landscape feature with information ABOUT those types of feature in everyday discourse. By publicly displaying such conceptual associations, such usages also serve to maintain those associations in the culture itself.

\section{3. phuu2 and phaa3 as 'far away'}

As discussed in Section 2.3, above, Lao speakers associate the two landscape features phuu2 'mountainous terrain' and phaa3 'vertical exposed rock face' with the notion of geographical isolation, places far from where people normally live. The common collocational expression phuu2-phaa3-paal-dong3, literally, 'mountain-cliff-forest-jungle', refers to the great outdoors (see Fig. 20). 


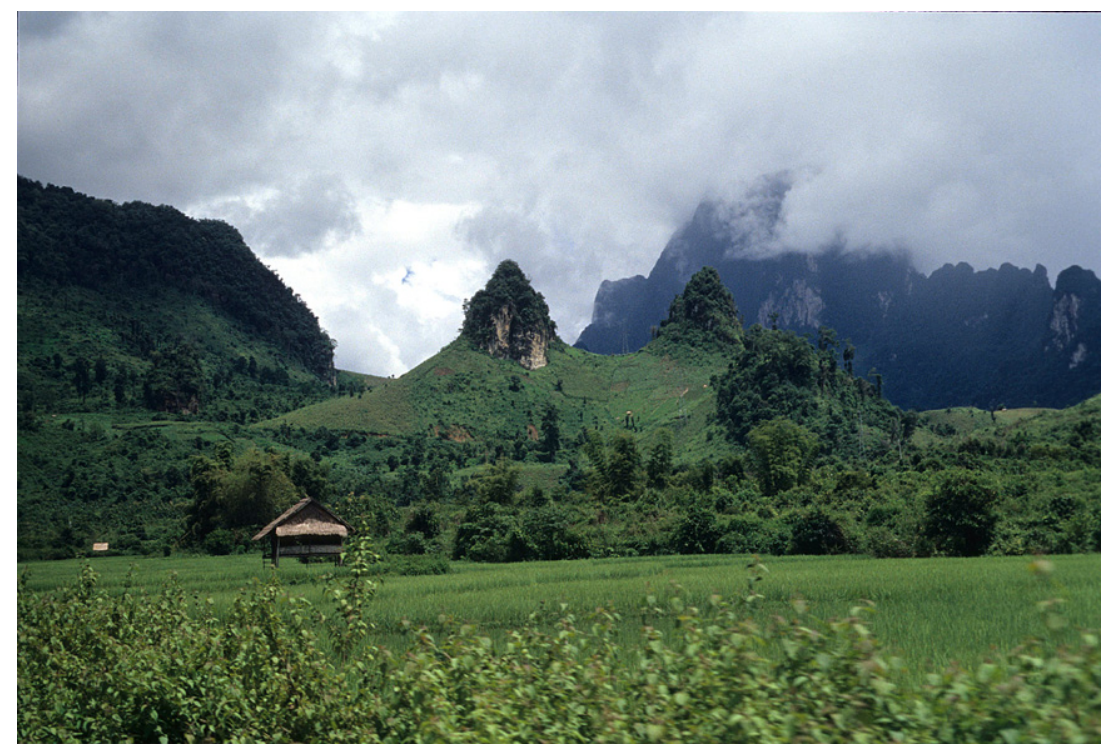

Fig. 20. Phuи2 'mountainous terrain' and phaa3 'exposed vertical rock faces'; emblematic of 'far away' from the village/town.

In an example from recorded conversation, two men are discussing the location of a certain village. They differ in opinion, arguing as to whether it is far away or nearby. In taking the position that it is far away, one speaker conveys this by using the terms phuu 2 'mountainous terrain' and phaa3 'vertical exposed rock face':

$\begin{array}{lllllll}\text { daj0 } & \text { piin3 } & \text { khùn5 } & \text { phaa3 } & \text { phuu2 } & \text { paj3 } & \text { han0 } \\ \text { must } & \text { climb } & \text { ascend } & \text { cliff } & \text { mountain } & \text { go } & \text { there }\end{array}$

'You have to climb up cliffs and mountains to go there.' (implying "it's far") (ref. 030806e_0620)

The association of 'far from where people live' with mountainous terrain is particularly deep-seated in Lao culture, given the historical heritage of Lao speakers, described in Section 2, above.

These few examples of spontaneous usage of landscape terms from daily conversation the primary site where linguistic categories are learned, maintained, and evolved illustrate how conversational reference to the landscape can both reveal and reinforce conceptual connections, as defined by human activities and perspectives, beyond the directly perceivable properties of these words' referents. This underscores the key role which corpus materials must play in future research on linguistic semantics.

\section{Concluding discussion}

The major distinctions Lao speakers make in their linguistic categorization of the physical landscape, as sketched in Section 2 of this article, do not have straightforward equiv- 
alents in English (or, no doubt, in most other languages). One possible reason for this is that only Lao speakers are confronted with this specific set of environmental distinctions. Perhaps given a particular environment, speakers' perceptual systems simply deliver a set of distinctions which determine the structure of the representations lexicalized in Lao. Or as Berlin puts it with reference to lexical distinctions in the domain of biological classification, 'the perceptually distinctive chunks that stand out as living landmarks ... guide the observer through and over the biological landscape' (Berlin, 1992, p. 290). This results in the lexical distinctions we observe. By this view, cross-linguistic diversity is a function of diversity of external structure in the referential world, since the properties of the human perceptual apparatus are assumed not to vary. The problem with this account is that while it might explain why a concept is shared in the minds of a community's members, it will not explain why it is PUBLICLY LABELED in that community. Lao speakers do not have words for coral boulders, lava-surrounded islands of earth, or freshwater reaches, presumably because these features are not encountered in the Lao-speaking environment. But the PRESENCE of some environmental feature does not guarantee it WILL BE LABELED (independent of whether such presence means that people in the community will possess the relevant non-linguistic categories). Further, the facts do not support a key prediction of the environmentally determinist account, i.e. that two languages traditionally spoken in the same environment will have the same systems of semantic distinction in the landscape domain. Levinson (this issue), discusses quite different systems of terminology in languages spoken in virtually identical environments (the comparison concerns features of the sea between the beach and the outer reefs in Yélî Dnye and Kilivila, two unrelated languages of Island Melanesia; cf. Senft, this issue).

A second possible reason that Lao landscape terms do not correspond directly to the semantics of landscape terms in other languages could be that Lao speakers have culture-specific practices in connection with their natural environment. Again, however, while Lao cultural practices may be unique, it is unclear how this would result in correspondingly unique patterns of lexicalization. There has to be a mechanism whereby cultural practices affect structure of the language itself (Enfield, 2002, p. 18; cf. Clark and Malt, 1984), and that mechanism is in the way people TALK ABOUT the categories (Simpson, 2002). Perception and cultural practice can only be distally causal here. A community's convergence on particular meanings for particular words is not a direct effect of perception or cultural practice, but is a secondary effect of those things, mediated though language use. That is, perception and cultural practices affect the conventionalization of word meaning only as far as they determine or constrain the things people say and the way they say them. It is patterns of talk that directly affect word learners' construction of linguistic categories. Word meanings are social, institutional facts (Searle, 1995), and as such require continual signaling of public agreement as to their value in order for them to exist and persist at all.

Accordingly, while it is "evidently possible for non-linguistic reality to serve as a guide to the categorization of speech" (Brown, 1958, p. 216), Brown warns that perceptual distinctions are not the key for linguistic categorization:

A child might learn to categorize the non-linguistic world from direct contact with its sensible attributes. He would begin by categorizing in terms of those attributes that have a kind of natural prepotency for him. Perhaps visual brightness is such an attribute. It would lead him to distinguish day from night, the sun from the moon, and 
white from black. Probably there are some universal categories imposed on all human beings by the prepotency of certain sensory attributes. But most of the categories we possess are cultural. For these the prepotent attributes are often irrelevant and sometimes misleading. A child might not have to learn to distinguish shiny coins from dull but these categories are poor equipment for the business world. (Brown, 1958, p. 208)

If perceptible discontinuities were the key source of structure for linguistic semantics, then we would autonomously arrive at the correct word meanings, more or less as the "constraints theorists" of word learning would have it (Clark, 1999). But children, like adults I would argue, are "far from autonomous in their assignments of possible meanings to unfamiliar words" (Clark, 1999, p. 16). Instead, they "make active use of the pragmatic information offered them ... about (a) which word to use, (b) how it differs in meaning from near neighbors, and (c) how it is related in meaning to other words in the same domain" (Clark, 1999, p. 16). From the point of view of the hearer, then, to learn or know a word is to develop or possess a satisfactory hypothesis as to what the word means - i.e. a hypothesis which is not falsified by the data. As Roger Brown argued, for the child learning a new word, 'a speech invariance is a signal to form some hypothesis about the corresponding invariance of referent' (Brown, 1958, p. 228). ${ }^{6}$ More memorably put, an unfamiliar word is a lure for cognition (Brown, 1958, p. 206). This reverses the usual way of thinking about word learning as process of 'labeling concepts'. Instead, by this account, it is more a matter of 'concepting labels', that is taking a label and then fleshing it out with conceptual content. The learner begins by identifying a new word form (as phonological category), then attempting to fill in its semantics, by trying to figure out what people 'must mean' when they use that phonological string. Even if word meanings were non-decomposable and necessarily innate (Fodor, 1975, 1998), the learner would still need to hypothesize, on the basis of data from communicative interaction, as to which meanings were connected to which labels. It is through linguistic usage like examples (2-6), above, that learners of Lao are able to construct semantic contents to fit the first-given labels.

On this view, it is entirely expected that the semantics of lexical systems of categorization of the landscape should vary across languages. Indeed, the puzzle then becomes: What kinds of forces could account for stability in semantic representation, within and across populations? (Cf. Sperber and Hirschfeld, 2004, p. 40). Why do speakers in a single community converge on linguistic meanings as closely as they do? Why do linguistic systems of categorization of the landscape look as similar across languages as they do? In some domains (e.g. color terminology), properties of the human perceptual apparatus are claimed to universally determine semantic patterns. If this is true, what needs to be explained is how the universals of perceptual and cognitive structure can weigh in upon word learners' processes of constructing word meaning in acquisition. It is an issue for further research: How is it that internal, privately represented categories in perception and cognition can determine structure in an inherently public set of categories such as the lexicon? The path cannot go directly from psychology to words. It has to be mediated by communicative practice.

\footnotetext{
${ }^{6}$ This allows semantic representations to differ significantly among individuals as long as the typical range of contexts of use allow different semantic hypotheses to remain equally viable. This point underlies the model of semantic change offered by Evans and Wilkins (2000; cf. Enfield, 2003).
} 


\section{Acknowledgements}

I gratefully acknowledge the Max Planck Society for field work and research support. Ludy Cilissen and Marloes Huijbers kindly and expertly assisted with the illustrations. I have benefited from discussion of the data and analysis with Melissa Bowerman, Niclas Burenhult, Steve Levinson, Asifa Majid, and Gunter Senft. I thank two anonymous reviewers for helping me improve upon an earlier version. All photographs are taken by the author, except for Fig. 11 (photographer unknown). All photographs are taken in Laos, except for Figs. 2a and 7, taken near the Laos-Vietnam border in So'n La Province, northern Vietnam.

\section{References}

Atkinson, J.M., Heritage, J. (Eds.), 1984. Structures of Social Action: Studies in Conversation Analysis. Cambridge University Press, Cambridge.

Barr, D.J., 2004. Establishing Conventional Communication Systems: Is Common Knowledge Necessary? Cognitive Science 28 (6), 937-962.

Barsalou, L.W., 1983. Ad hoc Categories. Memory and Cognition 11, 211-227.

Bateson, G., 1972. Steps to an Ecology of Mind. Ballantine Books, New York.

Berlin, B., 1992. Ethnobiological Classification: Principles of Categorization of Plants and Animals in Traditional Societies. Princeton University Press, Princeton, NJ.

Brown, R., 1958. Words and Things. The Free Press, Glencoe.

Claridge, G.F., Sorangkhoun, Thanongsi, Baird, I.G., 1997. Community Fisheries in Lao PDR: a Survey of Techniques and Issues. IUCN, Vientiane.

Clark, H.H., 1992. Arenas of Language Use. University of Chicago Press, Chicago.

Clark, H.H., 1996a. Communities, commonalities, and communication. In: Gumperz, J.J., Levinson, S.C. (Eds.), Rethinking Linguistic Relativity. Cambridge University Press, Cambridge, pp. 324-355.

Clark, H.H., 1996b. Using Language. Cambridge University Press, Cambridge.

Clark, E.V., 1999. Acquisition in the course of conversation. Studies in the Linguistic Sciences 29 (2), 1-18.

Clark, H.H., Malt, B.C., 1984. Psychological constraints on language: a commentary on Bresnan and Kaplan and on Givón. In: Kintsch, W., Miller, J.R., Polson, P.G. (Eds.), Methods and Tactics in Cognitive Science. Lawrence Erlbaum, Hillsdale, NJ, pp. 191-214.

Condominas, G., 1990. From Lawa to Mon, from Saa' to Thai. Historical and Anthropological Aspects of Southeast Asian Social Spaces. RSPAS, Canberra.

Dunbar, R.I.M., 1996. Grooming, Gossip and the Evolution of Language. Harvard University Press, Cambridge, MA.

Enfield, N.J., 2002. Ethnosyntax: introduction. In: Enfield, N.J. (Ed.), Ethnosyntax: Explorations in Culture and Grammar. Oxford University Press, Oxford, pp. 1-30.

Enfield, N.J., 2003. Linguistic Epidemiology: Semantics and Grammar of Language Contact in Mainland Southeast Asia. RoutledgeCurzon, London.

Enfield, N.J., 2004a. Nominal classification in Lao: a sketch. Sprachtypologie und Universalienforschung 57 (2/ 3), 117-143.

Enfield, N.J., 2004b. On linear segmentation and combinatorics in co-speech gesture: a symmetry-dominance construction in lao fish trap descriptions. Semiotica 149 (1/4), 57-123.

Enfield, N.J., 2005. Areal linguistics and mainland Southeast Asia. Annual Review of Anthropology 34, $181-206$.

Enfield, N.J., 2006a. Laos - language situation. In: Brown, K. (Ed.), Encyclopedia of Language and Linguistics, second ed. Cambridge University Press, Cambridge, pp. 698-700.

Enfield, N.J., 2006b. Social consequences of common ground. In: Enfield, N.J., Levinson, S.C. (Ed.), Roots of Human Sociality: Culture, Cognition, and Interaction. Berg, London, pp. 399-430.

Evans, N.D., in press. Semantic Typology. In: Song, J.J. (Ed.), The Oxford Handbook of Typology. Oxford University Press, Oxford.

Fodor, J.A., 1975. The Language of Thought. Harvard University Press, Cambridge, MA.

Fodor, J.A., 1998. Concepts: Where Cognitive Science Went Wrong. Oxford University Press, Oxford. 
Frege, Gottlob. 1892. On Sense and Reference. In Zeitschrift für Philosophie and philosophische Kritik 100, pp. $25-50$.

Gibson, J.J., 1979. The Ecological Approach to Visual Perception. Houghton Mifflin, Boston.

Grice, H.P., 1989. Studies in the Way of Words. Harvard University Press, Cambridge, MA.

Hunn, E., 1982. The utilitarian factor in folk biological classification. American Anthropologist 89, 146-149.

Hunn, E., 1985. The utilitarian factor in folk biological classification. In: Dougherty, J.W.D. (Ed.), Directions in Cognitive Anthropology. University of Illinois Press, Urbana, pp. 117-140.

Kockelman, P., 2005. The Semiotic Stance. Semiotica 157, 233-304.

Kockelman, P., 2006. Residence in the World: affordances, instruments, actions, roles, and identities. Semiotica $162,19-72$.

Langacker, R.W., 1987. Foundations of Cognitive Grammar: Volume I. In: Theoretical Prerequisites, 1. Stanford University Press, Stanford.

Leach, E., 1964. Political Systems of Highland Burma. The Athlone Press, London.

Levinson, S.C., 1995. Interactional biases in human thinking. In: Goody, E. (Ed.), Social Intelligence and Interaction: Expressions and Implications of the Social Bias in Human Intelligence. Cambridge University Press, Cambridge, pp. 221-260.

Lewis, D.K., 1969. Convention: a Philosophical Study. Harvard University Press, Cambridge, MA.

Murphy, G.L., 2002. The Big Book of Concepts. MIT Press, Cambridge, MA.

Peirce, C.S., 1932. Speculative Grammar. In: Hartshorne, C., Weiss, P. (Eds.), Collected Papers of Charles Sanders Peirce. Elements of Logic, vol. II. The Belknap Press of Harvard University Press, Cambridge, MA, pp. 127-269.

Prinz, J.J., 2002. Furnishing the Mind: Concepts and Their Perceptual Basis. MIT Press, Cambridge, MA.

Saussure, F., 1916. Course in General Linguistics. McGraw-Hill, New York.

Schelling, T.C., 1960. The Strategy of Conflict. Harvard University Press, Cambridge, MA.

Schiffer, S.R., 1972. Meaning. Clarendon Press, Oxford.

Searle, J.R., 1995. The Construction of Social Reality. The Free Press, New York.

Simpson, J., 2002. From common ground to syntactic construction: associated path in Warlpiri. In: Enfield, N.J. (Ed.), Ethnosyntax: Explorations in Grammar and Culture. Oxford University Press, Oxford, pp. 287-308.

Sperber, D., 1985. Anthropology and psychology: towards an epidemiology of representations. Man 20, 73-89.

Sperber, D., Hirschfeld, L.A., 2004. The cognitive foundations of cultural stability and diversity. Trends in Cognitive Sciences 8 (1), 40-46.

Stivers, T., Enfield, N.J., Levinson, S.C., 2007. Person reference in interaction. In: Enfield, N.J., Stivers, T. (Eds.), Person Reference in Interaction: Linguistic, Cultural, and Social Perspectives. Cambridge University Press, Cambridge, pp. 1-20.

Taylor, J.R., 1989. Linguistic Categorization: Prototypes in Linguistic Theory. Clarendon Press, Oxford.

Wierzbicka, A., 1984. Apples are not a kind of fruit. American Ethnologist 11 (2), 313-328.

Wierzbicka, A., 1985. Lexicography and Conceptual Analysis. Karoma, Ann Arbor.

Wierzbicka, A., 1989. Baudouin de Courtenay and the theory of linguistic relativity. In: Janusz Rieger, Mieczyslaw Szymczak, Stanislaw Urbanczyk (Eds.), Jan Niecislaw Baudouin de Courtenay a lingwistyka swiatowa. Wroclaw, Ossolineum, pp. 51-57.

Wyatt, D.K., 1984. Thailand: a Short History. Silkworm Books, Chiang Mai. 